\title{
Damage Evolution of Steel-Polypropylene Hybrid Fiber Reinforced Concrete: Experimental and Numerical Investigation
}

\author{
Lihua Xu, Cuimei Wei, and Biao Li (iD \\ School of Civil Engineering, Wuhan University, Wuhan 430072, China \\ Correspondence should be addressed to Biao Li; libiao@whu.edu.cn
}

Received 11 June 2018; Accepted 8 November 2018; Published 12 December 2018

Academic Editor: Jun Liu

Copyright (C) 2018 Lihua Xu et al. This is an open access article distributed under the Creative Commons Attribution License, which permits unrestricted use, distribution, and reproduction in any medium, provided the original work is properly cited.

\begin{abstract}
This paper presents an experimental investigation on the stress-strain behavior and damage evolution of steel-polypropylene hybrid fiber reinforced concrete (HFRC) with different fiber types, volume fractions, and aspect ratios. The damage evolution laws of HFRC were obtained using uniaxial cyclic compression and tension tests. The results show that the addition of hybrid fiber has a significant synergetic effect on the mechanical behavior of concrete. The peak strength, peak strain, toughness, and postpeak ductility of HFRC under both tension and compression are improved, and the damage accumulation and stiffness degradation are alleviated by increasing volume fractions of SF and PF, as well as aspect ratios of SF. Moreover, the steel fiber volume fraction shows a more pronounced effect than that of other considered factors on the enhancement of cyclic mechanical parameters of HFRC. Based on the unloading stiffness degradation process, analytical equations were, respectively, proposed to generalize the damage progression of HFRC under compression and tension, with the effects of hybrid fiber taken into consideration. Finally, the proposed uniaxial damage evolution equations combined with the calibrated concrete damaged plasticity (CDP) model in ABAQUS were used to predict the responses of HFRC materials and structural members subjected to shear and seismic loads. The comparisons between the numerical predictions and experimental results show a good agreement.
\end{abstract}

\section{Introduction}

Over the last decades, fiber reinforced concrete (FRC) has achieved rapid development and application in the field of civil engineering, which shows higher cracking resistance, toughness, tensile strength, postcracking ductility, fatigue, and seismic performance than the traditional one. Single FRC has been widely investigated in lots of experimental, numerical, and theoretical studies [1-9]. However, the fracture in concrete is a gradual and multiscale process, occurring at both micro- and macrolevels due to the high heterogeneity of concrete matrix $[10,11]$. Therefore, it is very limiting when only using one type and dimension of fibers as the reinforcements and logical to employ the combination of fibers with different sizes, functions, and mechanics for an optimal behavior of concrete. In this sense, hybrid fiber reinforced concrete (HFRC), containing both steel fiber (SF) and polypropylene fiber (PF), has gained increasing recognition for its superior performance and has become a promising material $[12,13]$.
The structural design and applications of HFRC should have a deep and comprehensive understanding of its mechanical behavior and constitutive model. Given this, $\mathrm{Xu}$ et al. [14-21] systematically investigated the mechanical behaviors of HFRC under uniaxial monotonic/cyclic compression and tension as well as the true triaxial compression, and based on the corresponding test results, constitutive equations were proposed to predict the mechanical responses of HFRC materials. Moreover, they also reported the experimental results of behaviors of HFRC structural members, i.e., short beams, deep beams, columns, beamcolumn joints etc., subjected to shear, flexure, and seismic loads. Meanwhile, results of the mechanical behaviors of HFRC materials and structural members with respect to the basic mechanical properties, flexural and seismic performance, etc., were also reported by other researchers [22-26]. In addition, corresponding models for HFRC were established using the multiphase micromechanics and elastoplastic concept $[27,28]$. However, it should be mentioned that the failure of HFRC is mainly determined by the damage 
accumulation subjected to the external loads. The damage in HFRC should have a deep research and be considered in the establishment of the constitutive model. Of the limited few research studies on the damage constitutive models of HFRC, the work conducted by Chi et al. [29] is worth quoting. The proposed model is a modification of the concrete damaged plasticity (CDP) model in ABAQUS using the experimental results. The damage evolution laws are modified by previous studies based on some assumptions. Moreover, lots of theoretical models of FRC using damage mechanics are developed by previous researchers; however, the damage in those models is also transferred from the test results under uniaxial loading cases [30-34]. Therefore, what the real damage evolution process in HFRC is and how the fibers affect the damages should be investigated deeply. It is well known that the cyclic loading test is one of the most direct methods to measure the damage evolution laws of materials [35-44]. The damage in concrete can be quantitatively characterized by the unloading stiffness degradation process. Accordingly, the same test methods are also adopted in this work to measure the damage of HFRC.

From the above literature review, the objective of this paper is to study the stress-strain behavior and damage evolution of HFRC. For this aim, uniaxial cyclic compressive and tensile tests on the HFRC specimens with different fiber types, volume fractions, and aspect ratios were conducted. Analytical formulae for the damage evolution laws of HFRC under compression and tension were respectively proposed based on the unloading stiffness degradation process. Finally, the CDP model in the finite element software ABAQUS for HFRC was calibrated, with the key parameters and two set of uniaxial monotonic stress-strain relations modified by the authors' previous studies. Then, the model was validated by the experimental results using ABAQUS at both the material and structural scales.

\section{Experimental Program}

2.1. Materials and Specimen Preparation. Ordinary Portland cement $42.5 \mathrm{R}$ was employed as the binder. Crushed granitic rocks of sizes of 5-20 $\mathrm{mm}$ were used as the coarse aggregates. Normal river sands with the maximum size of $5 \mathrm{~mm}$ were used as the fine aggregates. The grading curves of the aggregates are presented in Figure 1. A highly efficient water reducer with a reducing rate of about $20 \%$ was adopted. The mix proportions of plain concrete designed according to the Code JGJ 55-2011 [45] are given in Table 1.

Two different types of fibers were considered, namely, SF and PF. The corresponding material properties are given in Table 2. According to the previous studies [20-24], the volume fractions of SF were selected as $1.0 \%, 1.5 \%$, and $2.0 \%$, and the aspect ratios of 30,60 , and 80 were adopted in this work. In addition, monofilament PF with the low volume fractions of $0.1 \%, 0.15 \%$, and $0.2 \%$ was, respectively, used. The details of the specimens are listed in Table 3.

The design of specimens is in accordance to the Chinese Standards CECS 13:2009 [46]. In this work, prismatic specimens with a dimension of $150 \mathrm{~mm} \times 150 \mathrm{~mm} \times 300 \mathrm{~mm}$ were prepared for the compression tests, and cylindrical

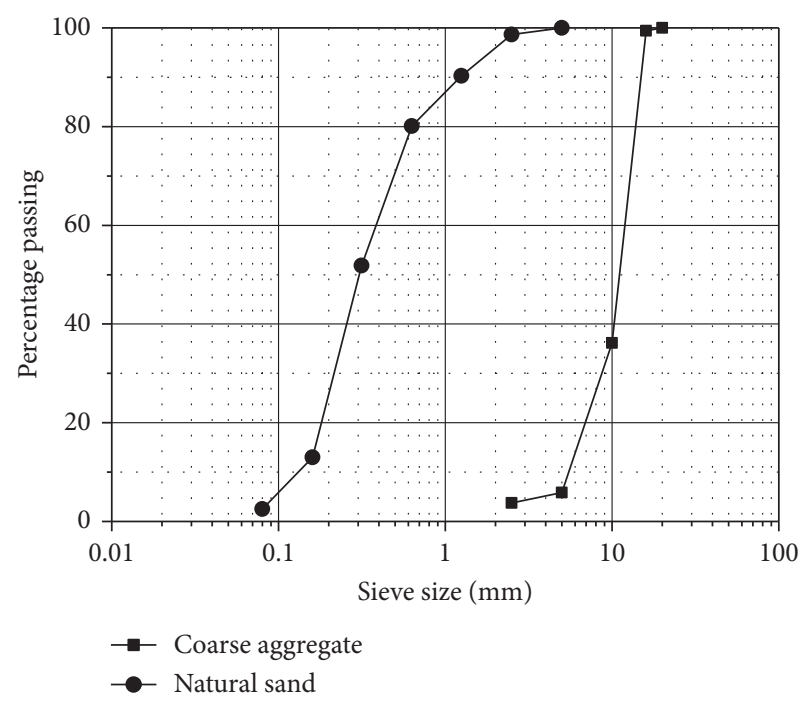

Figure 1: Grading curves for fine and coarse aggregates.

TABle 1: Designed concrete mix proportions $\left(\mathrm{kg} / \mathrm{m}^{3}\right)$.

\begin{tabular}{lccccc}
\hline Cement & Sand & Gravel & Water & Superplasticizer & $\begin{array}{c}\text { Water } \\
\text { cement ratio }\end{array}$ \\
\hline 417 & 724 & 1086 & 175 & 2.1 & 0.42 \\
\hline
\end{tabular}

specimens with the diameter of $75 \mathrm{~mm}$ and height of $200 \mathrm{~mm}$ were used for the tension tests. For each concrete mixture, three specimens were fabricated for each loading case in order to achieve an average value.

All the specimens were fabricated in accordance to the Chinese Standard CSCE 38:2004 [47]. After uniform mixing, the fresh concrete was cast into the prepared forms. After 24 hours, the specimens were demoulded and then stored in a standard curing room until the 28-day strength was achieved. In addition, for each case, six cubes with the side length of $150 \mathrm{~mm}$ were cast for determining the compressive strength and splitting tensile strength of concrete. The test results from averaging a group of three are summarized in Table 3.

2.2. Test Setup. The cyclic compressive tests were performed on a universal electrohydraulic servo rock testing machine, INSTRON-1346, as shown in Figure 2(a). Two linear variable displacement transducers (LVDT \#1 and LVDT \#2) with a maximal range of $5 \mathrm{~mm}$ were used to measure the vertical displacement, and the lateral displacements were monitored by LVDT \#3 and LVDT \# 4 with a maximal range of $2.5 \mathrm{~mm}$. The axial loads and displacements were automatically recorded to the data acquisition system with a synchronized frequency of $50 \mathrm{~Hz}$ and then stored in a computer.

The uniaxial tension tests were conducted on a universal electrohydraulic servo rock mechanics test machine, MTS 815 , with a load bearing capacity of $10000 \mathrm{kN}$, as shown in Figure 2(b). During the loading process, two extensometers (\#1 and \#2) were used to measure the vertical strain of 
TABLE 2: Major properties of fibers.

\begin{tabular}{|c|c|c|c|c|c|c|c|}
\hline Fiber species & No. & Aspect ratio & $\begin{array}{c}\text { Equivalent } \\
\text { diameter }(\mathrm{mm})\end{array}$ & Fiber type & $\begin{array}{l}\text { Density } \\
\left(\mathrm{g} / \mathrm{cm}^{3}\right)\end{array}$ & $\begin{array}{c}\text { Tensile strength } \\
(\mathrm{MPa})\end{array}$ & Feature \\
\hline & $\begin{array}{l}\text { SA } \\
\text { SB }\end{array}$ & $\begin{array}{l}30 \\
60\end{array}$ & & & & & \\
\hline Steel fiber & SC & 80 & 0.55 & Corrugated type & 7.8 & $\geq 600$ & \\
\hline Polypropylene fiber & PA & 167 & 0.048 & Monofilament type & 0.91 & $\geq 400$ & \\
\hline
\end{tabular}

TABle 3: Details of specimens.

\begin{tabular}{|c|c|c|c|c|c|c|c|}
\hline \multirow[b]{2}{*}{ No. } & \multirow[b]{2}{*}{ Specimens } & \multicolumn{2}{|c|}{ SF } & \multicolumn{2}{|c|}{$\mathrm{PF}$} & \multirow[b]{2}{*}{$f_{\mathrm{cu}}(\mathrm{MPa})$} & \multirow[b]{2}{*}{$\begin{array}{c}f_{\text {st }} \\
(\mathrm{MPa})\end{array}$} \\
\hline & & $\begin{array}{l}V_{\mathrm{sf}} \\
(\%)\end{array}$ & $l_{\mathrm{sf}} / d_{\mathrm{sf}}$ & $\begin{array}{l}V_{\mathrm{pf}} \\
(\%)\end{array}$ & $l_{\mathrm{pf}} / d_{\mathrm{pf}}$ & & \\
\hline 1 & S000P000 & - & - & - & - & 47.53 & 2.75 \\
\hline 3 & SB15P000 & 1.50 & 60 & - & - & 52.91 & 4.47 \\
\hline 4 & S000P15 & - & - & 0.15 & 167 & 48.80 & 3.47 \\
\hline 7 & SB10PA15 & 1.00 & 60 & 0.15 & 167 & 55.2 & 4.13 \\
\hline 8 & SB15PA10 & 1.50 & 60 & 0.10 & 167 & 58.05 & 4.61 \\
\hline 9 & SA15 & 1.50 & 30 & 0.15 & 167 & 54.65 & 4.19 \\
\hline 10 & SB15PA15 & 1.50 & 60 & 0.15 & 167 & 53.35 & 4.25 \\
\hline 13 & SC15PA15 & 1.50 & 80 & 0.15 & 167 & 53.70 & 4.76 \\
\hline 14 & SB15PA20 & 1.50 & 60 & 0.20 & 167 & 50.91 & 3.76 \\
\hline 15 & SB20PA15 & 2.00 & 60 & 0.15 & 167 & 56.22 & 5.36 \\
\hline
\end{tabular}

specimens. The gauge length is $100 \mathrm{~mm}$, and the precision is $0.001 \mathrm{~mm}$. The displacements and axial loads were automatically recorded in a computer. In this loading system, in order to avoid the loading eccentricity, the steel link chine and spherical hinge were designed. Moreover, the specimens were stuck to the steel plates using a construction structural adhesive. Furthermore, in order to avoid the debonding between steel and specimens, steel lantern rings with an internal diameter of $77 \mathrm{~mm}$ and a height of $25 \mathrm{~mm}$ were used. The internal side faces of them were mounted to the bottom and top of the specimens in order to increase the lateral shear strength along with the loading direction of specimens, and the bottoms were stuck to the steel plates.

2.3. Loading Procedure. Hierarchical loading method with a displacement control load was used for both compressive and tensile tests, as shown in Figure 3. At the beginning of each test, a preloading of approximate $10 \%$ of the ultimate compressive/tensile strengths was applied. For the cyclic compression, the loading was divided into two steps. In the prepeak region (stage I), the displacement increment in each step was $0.15 \mathrm{~mm}$ with a loading speed of $0.01 \mathrm{~mm} / \mathrm{s}$, and in the postpeak region (stage II), the displacement increment was set to $0.3 \mathrm{~mm}$. The unloading process was a control load with a speed of $10 \mathrm{kN} / \mathrm{s}$ to the ultimate unloading load of $0.5 \mathrm{kN}$. The test was terminated once the displacement limited value of $4.2 \mathrm{~mm}$ was reached. For the cyclic tensile loading case, the displacement increment which was the forward displacement of electrohydraulic actuator was set as $0.3 \mathrm{~mm}$, with a loading speed of $0.0006 \mathrm{~mm} / \mathrm{s}$. Moreover, the unloading path was load controlled with a speed of $0.3 \mathrm{kN} / \mathrm{s}$ and was unloaded to $0.5 \mathrm{kN}$. The test was terminated when the displacement of $3.3 \mathrm{~mm}$ was reached. However, it should be noted that in order to avoid the unloading at the regions of peak stress, the displacement of $0.9 \mathrm{~mm}$ was not considered under both tension and compression in this study.

\section{Experimental Results}

\subsection{Cyclic Stress-Strain Curves}

3.1.1. Under Compression. The typical stress-strain curves of HFRC under cyclic compression are shown in Figure 4. In order to analyze the effects of hybrid fiber on the mechanical behavior, the corresponding envelope curves referenced as the upper boundary of the cyclic responses of the specimens are illustrated in Figure 5. The following results are found:

(a) Performance Degradation. Remarkable stiffness degradation and stress deterioration are observed for all the curves, which differ widely for different fiber parameters. The initial unloading path is almost vertical with an abrupt stress drop for a small strain increment; however, when the curve accesses the strain axis, the curvature of the unloading path turns larger. For the reloading path, significant stress deterioration is seen in comparison with the envelope stress at the same unloading strain, which is caused by the crack propagation and damage accumulation. 

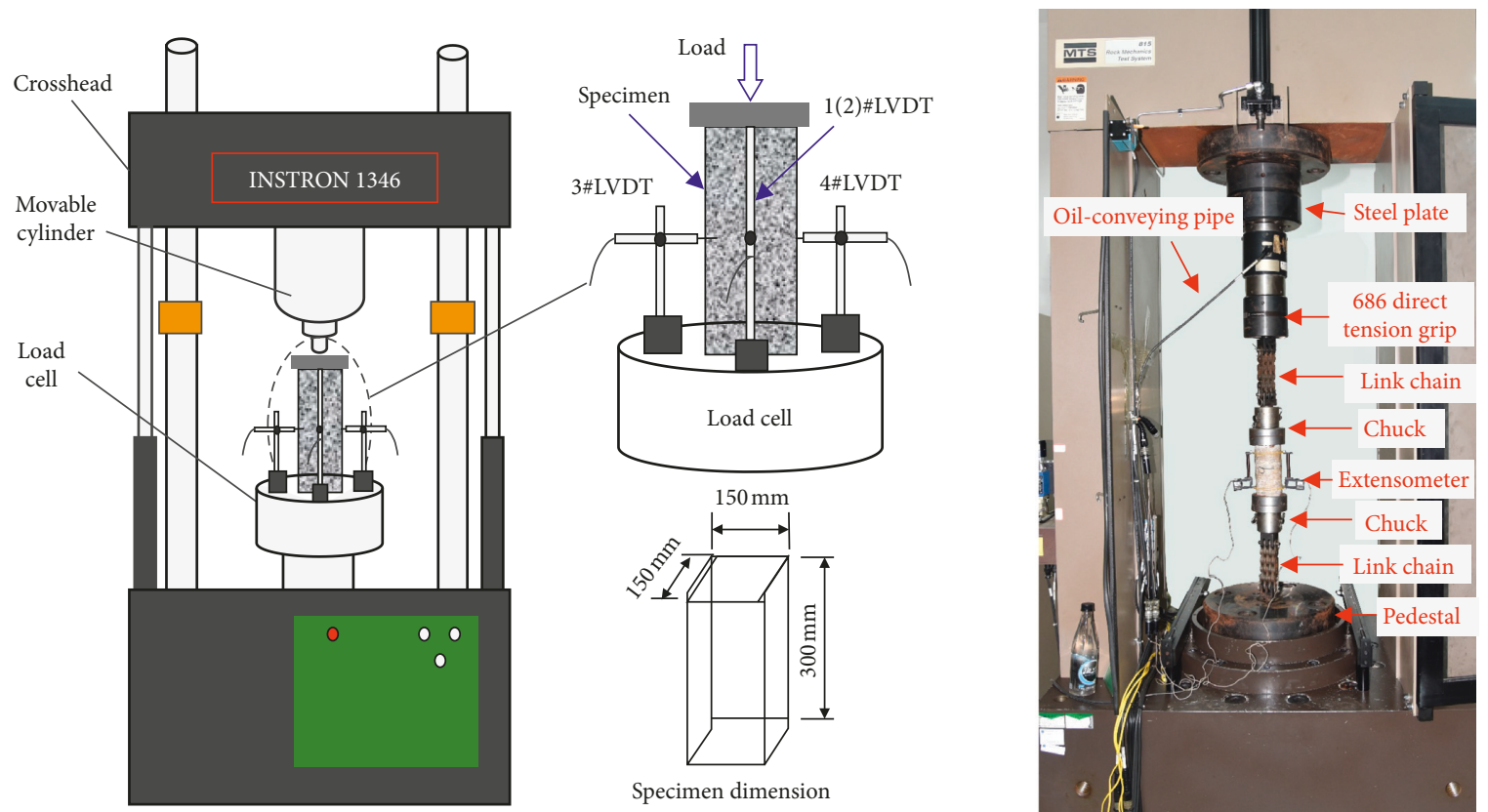

Figure 2: Schematic diagram of experimental setups for (a) compression tests and (b) tension tests.

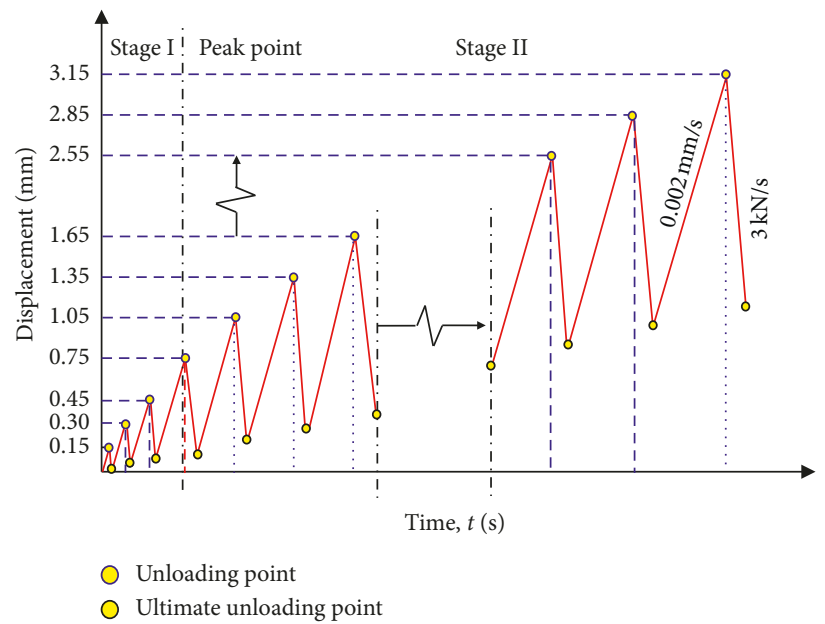

(a)

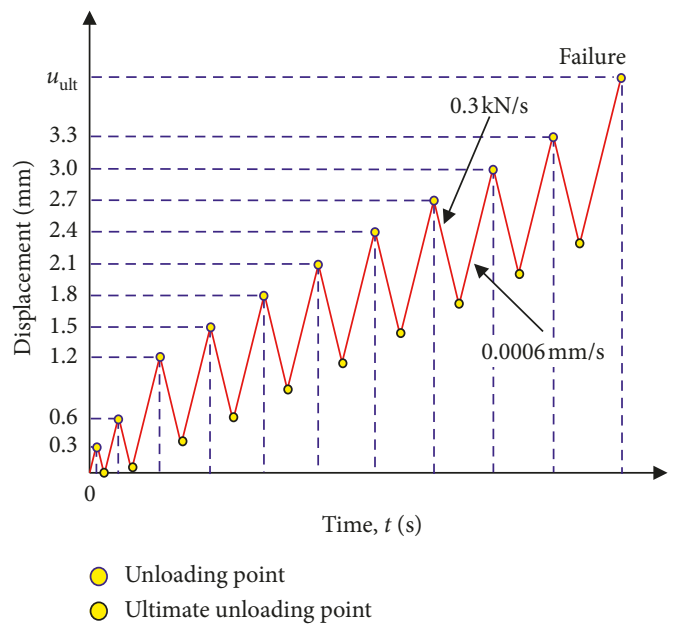

(b)

FIGURE 3: Schematic diagram of cyclic loading procedure. (a) Under compression. (b) Under tension.

(b) Energy Dissipation. Prior to the peak stress, the unloading path is almost overlapping with the reloading path because the concrete specimen almost remains elastic, where the hysteretic energy dissipation is not evident. However, in the postpeak region, the hysteretic loop becomes more obvious as the loading cycles increase. Moreover, the hysteretic energy dissipation capacity of FRC is stronger than that of plain concrete, where a small hysteretic loop after the peak stress is observed, and it fades away with increasing loading cycles. The phenomenon is attributed to debondings between aggregate and matrix in plain concrete. With respect to HFRC, the energy dissipation remains active. At the failure stage, fiber sliding and pullout are the main contributors to the energy dissipation.

(c) Load Drop. In general, the stress-strain curves of FRC are smoother than those of plain concrete. For FRC, the load drops are slighter when compared to plain concrete owing to the fiber crack-bridging effect. Moreover, a slower rate of stiffness degradation is found for SFRC, which is consistent with the observations in Reference [37].

(d) Envelope Curve. Fibers mainly affect the postpeak response. When adding SFs into concrete, an enhancement in the peak stress is observed, and the deterioration in strength and unloading stiffness is 


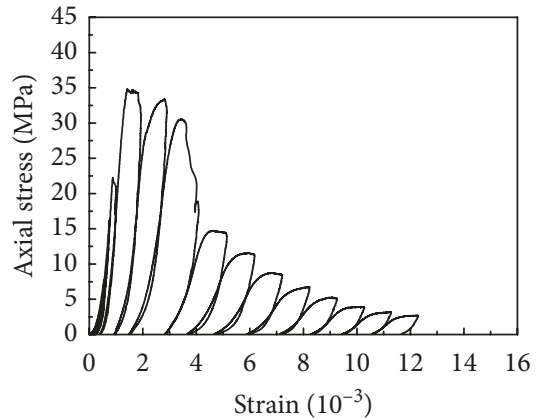

- S000P000

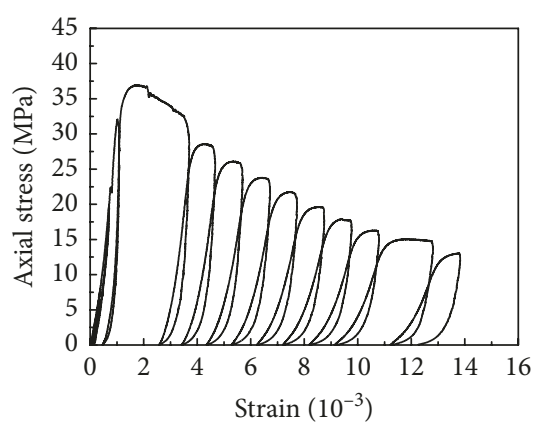

— SB10PA15

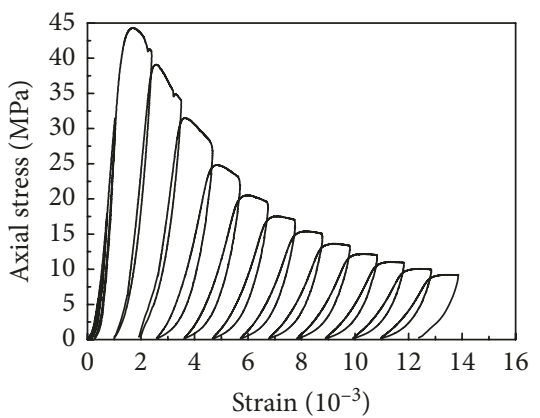

- SA15PA15

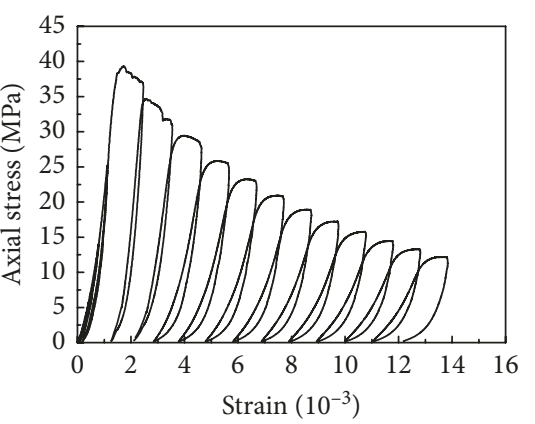

— SB15PA10

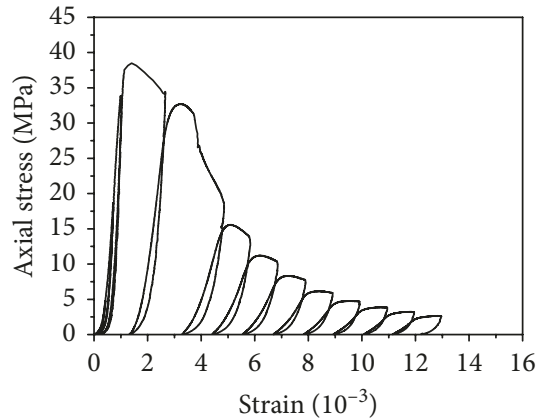

- S000PA15

(a)

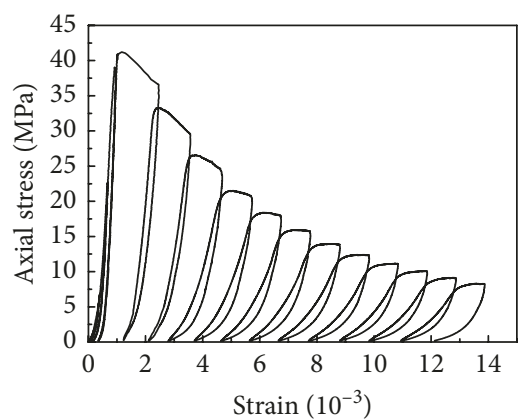

— SB15PA15

(b)

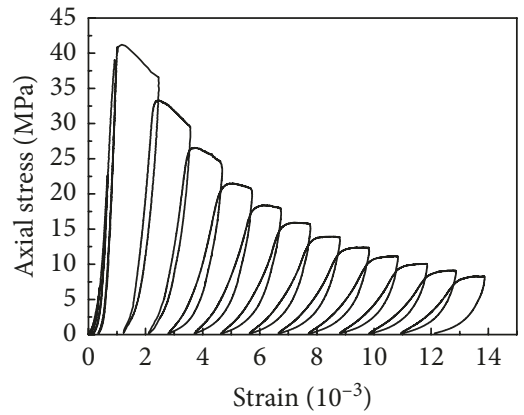

- SB15PA15

(c)

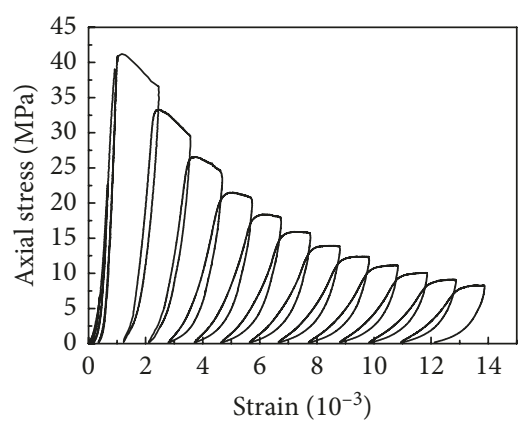

- SB15PA15

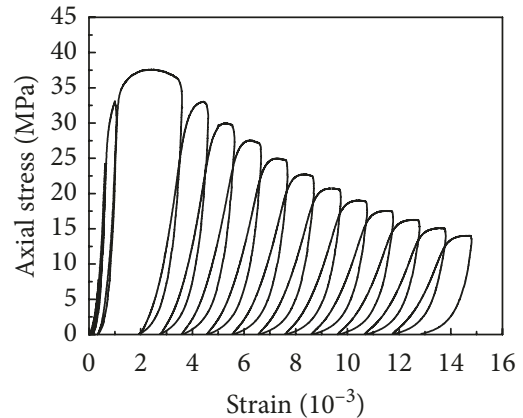

- SB15P000

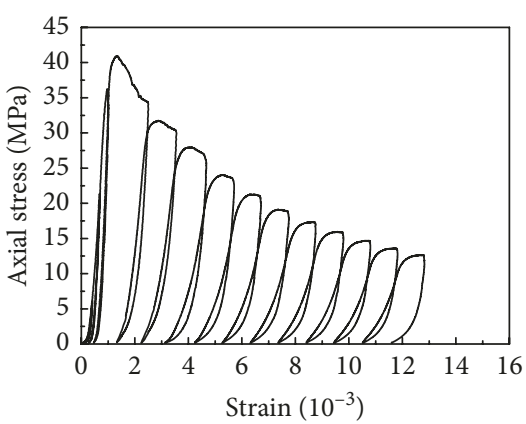

- SB20PA15

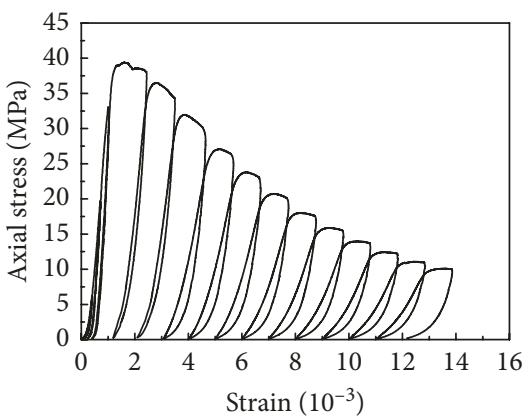

- SC15PA15

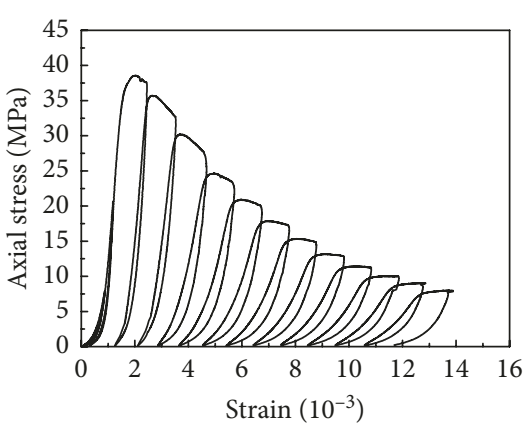

- SB15PA20

(d)

FIGURE 4: Cyclic stress-strain relations of the HFRC specimen: (a) effect of fiber type; (b) effect of volume fraction of SF; (c) effect of aspect ratio of SF; (d) effect of volume fraction of PF. 


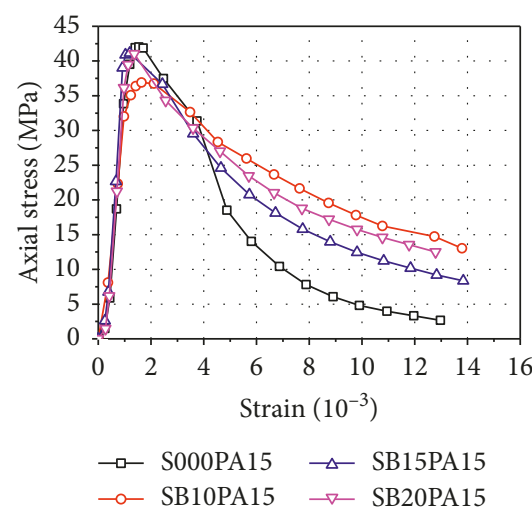

(a)

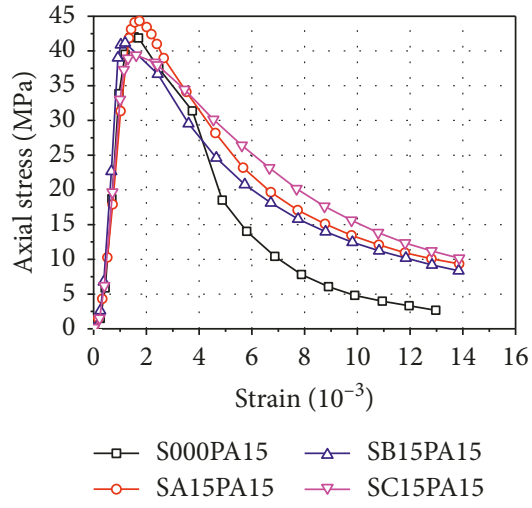

(b)

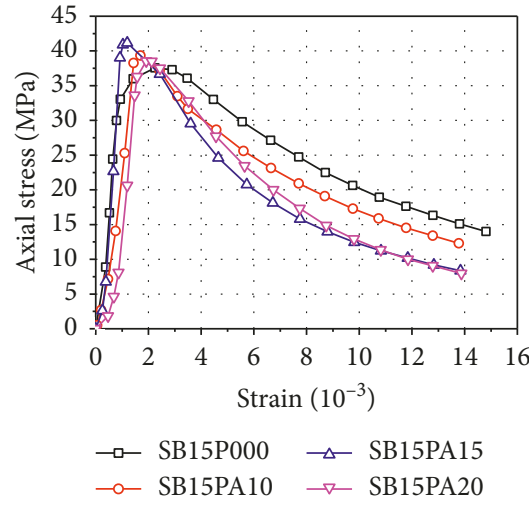

(c)

FIGURE 5: Cyclic envelope curves of HFRC: (a) effect of volume fraction of SF; (b) effect of aspect ratio of SF; (c) effect of volume fraction of PF.

slighter than that of PFRC. The peak stress increases as the fiber volume fraction increases and decreases with increasing fiber aspect ratio. In addition, the effects of SF for various fiber parameters on the ductile behavior have a small undulation under cyclic loading. With respect to PF, it is found that the addition of $\mathrm{PF}$ has a slight improvement on the peak stress of HFRC, but the stress deterioration is more significant than that of SFRC. Therefore, it can be concluded that the hybrid effect of PF and SF is positive on the peak strength of concrete, in spite that the effect of PF fluctuates slightly. However, adding PFs into concrete has insignificant effects on the ductility of concrete when subjected to the cyclic loads, which can be interpreted that the initial damages such as microdefects increase with increasing volume fractions of $\mathrm{PF}$.

3.1.2. Under Tension. Figure 6 shows the typical stress-strain curves of HFRC under cyclic tension. The corresponding envelope curves are plotted in Figure 7 . The following results can be seen from these figures:

(a) Performance Degradation. Unloading stiffness and strength degradations are observed for all the stressstrain curves. Before the peak stress, the unloading stiffness is near to the initial elastic stiffness. However, after the peak stress, the unloading stiffness decreases with increasing loading cycles.

(b) Energy Dissipation. Alike the phenomenon under compression, the hysteretic loop formed by the unloading and reloading paths is insignificant for both the pre- and postpeak branches. Moreover, the effects of fiber parameters on the energy dissipation of HFRC are also insignificant.

(c) Load Drop. For plain concrete and PFRC, a sudden load drop to zero at the peak stress is observed, with no descending branch. For specimens with steel fibers, the load drops are small owing to the steel fiber crack-bridging effect, with an obvious flat descending branch, especially for high fiber volume fractions. (d) Envelope Curve. The envelope curves of HFRC can be approximately divided into two branches: ascending branch and descending branch. At the former, the stress is almost linearly increasing to the peak stress of concrete. While, at the descending branch, the stress has a sharp drop at the peak strain and then decreases with increasing axial strain. Moreover, the addition of hybrid fiber has a significant effect on the stress-strain behavior of HFRC, for both the pre- and postpeak stages. All the ascending branches of the envelope curves are linear. However, the peak loads and load drops at the peak strain are affected remarkably by the fiber parameters. The peak strength, peak strain, toughness, and postpeak ductility all increase with increasing fiber volume fractions and steel fiber aspect ratio. The two kinds of used fibers exhibit an obvious synergetic effect.

3.2. Stiffness Degradation. Stiffness degradation is an important aspect to reflect the damage degree and its evolution of concrete, which can be characterized by the variations of reloading/unloading modulus during cyclic loading [40]. In this study, as a simplified calculation rule, the slope between the unloading point and ultimate unloading point is defined as the unloading elastic modulus. Moreover, a stiffness ratio $R_{s}$ is defined and used to characterize the damage of HFRC:

$$
R_{\mathrm{s}}=\frac{E_{\mathrm{unl}}}{E_{0}}
$$

where $R_{\mathrm{s}}$ is the stiffness ratio, $E_{0}$ is the initial elastic stiffness of concrete, and $E_{\text {unl }}$ is the unloading stiffness for a loading cycle.

3.2.1. Under Compression. The stiffness degradation process of HFRC under cyclic compression is shown in Figure 8. It is found that in general, the process can be divided into two stages: descending stage and stable stage. At the descending branch, an obvious drop in the unloading stiffness is observed. The stiffness ratio decreases with increasing envelope unloading strain due to the initial damage propagation 


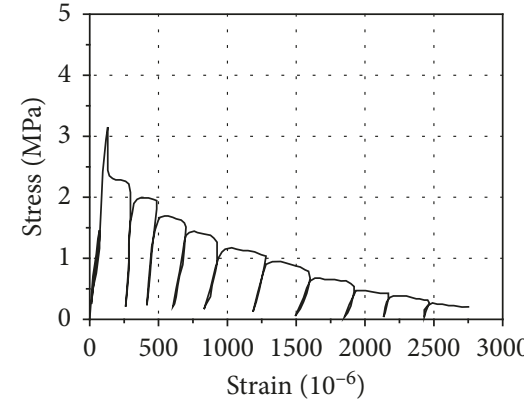

— SB10P15

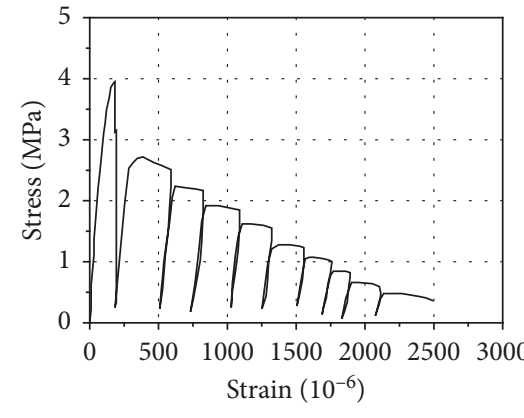

— SA15P15

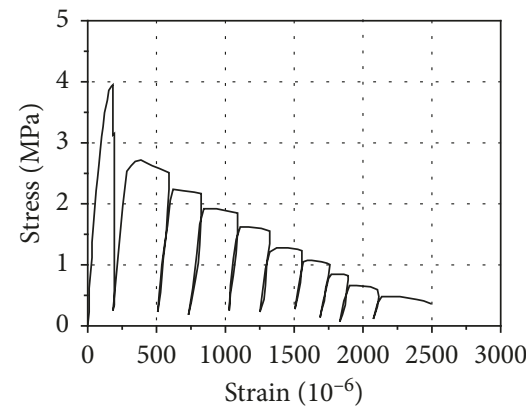

— SB15P10

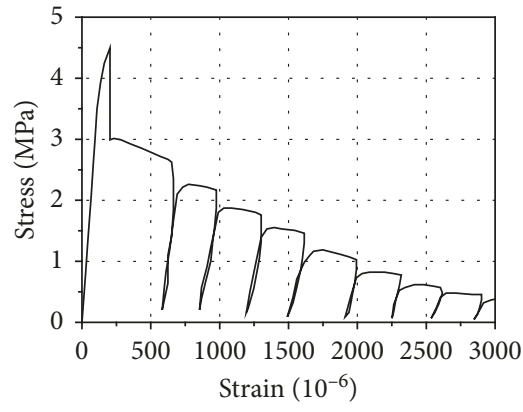

- SB15P15

(a)

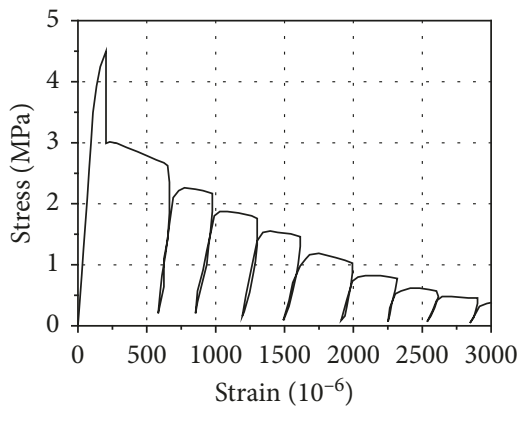

(b)

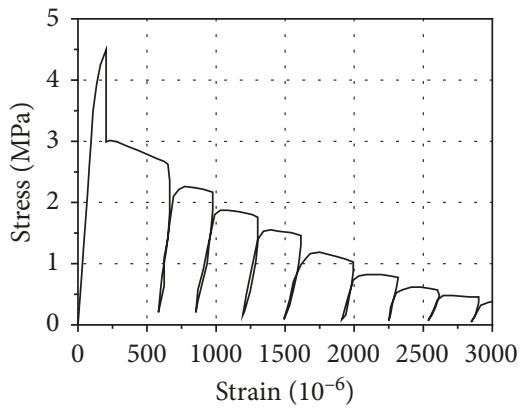

— SB15P15

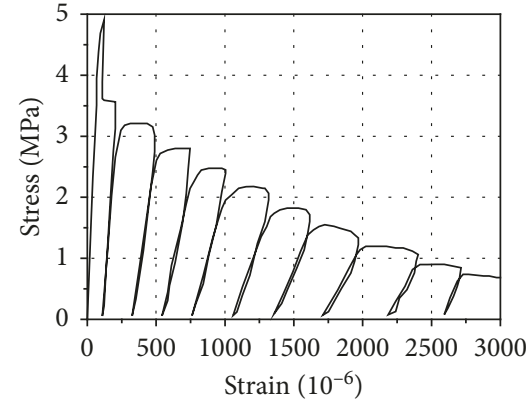

— SB20P15



- SC15P15

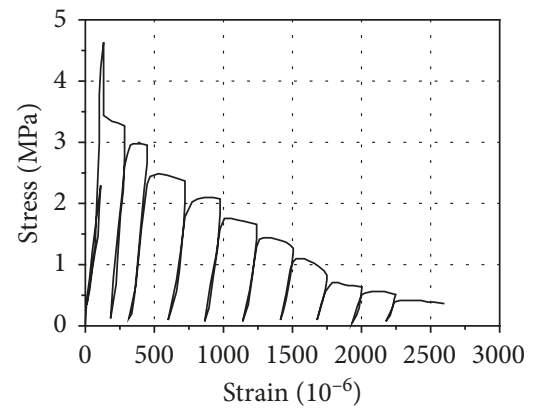

— SB15P20

(c)

FIGURE 6: Stress-strain relations of HFRC under cyclic tension: (a) effect of volume fraction of SF; (b) effect of aspect ratio of SF; (c) effect of volume fraction of PF.

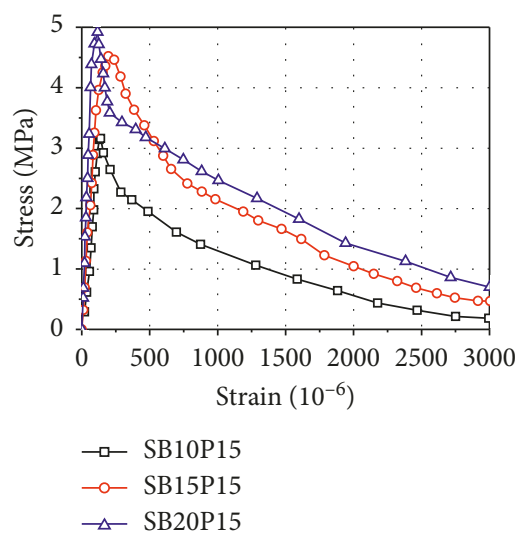

(a)

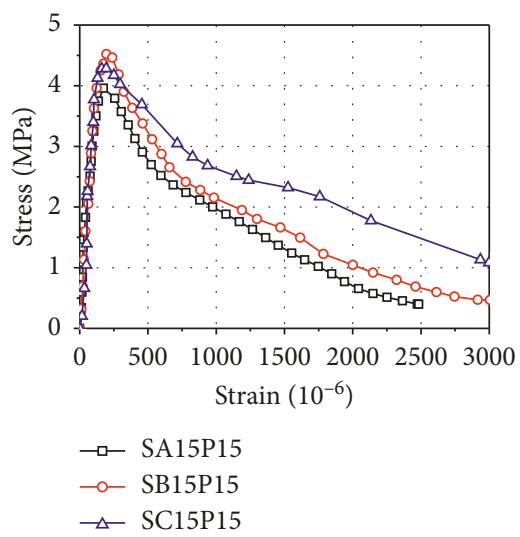

(b)

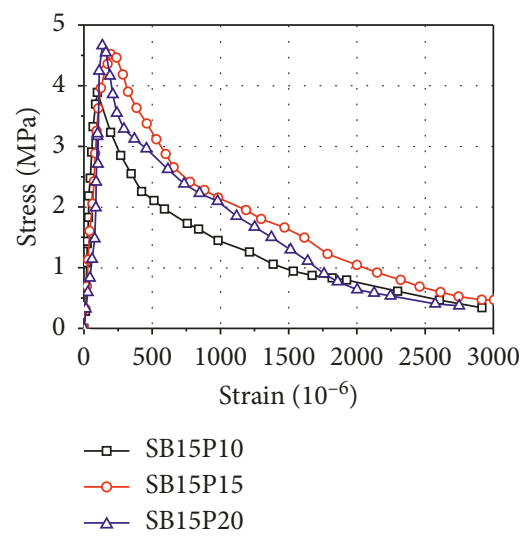

(c)

FIGURE 7: Envelope curves of HFRC under cyclic tension: (a) effect of volume fraction of SF; (b) effect of aspect ratio of SF; (c) effect of volume fraction of PF. 


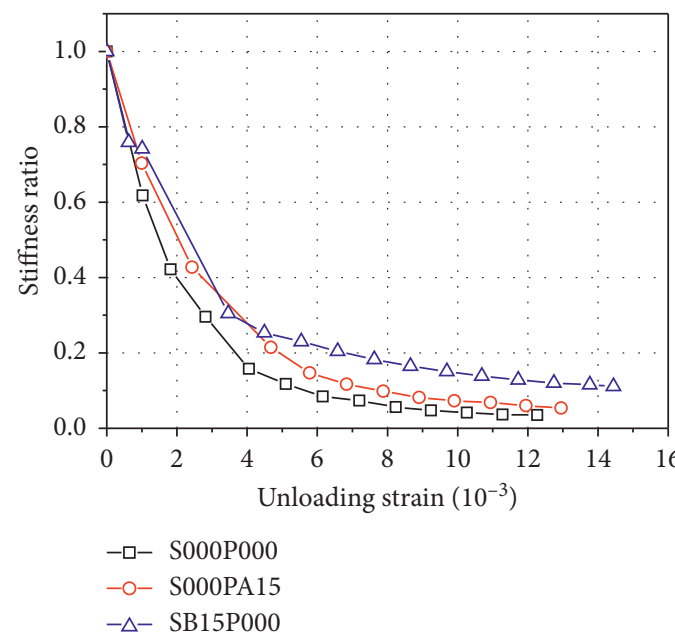

(a)

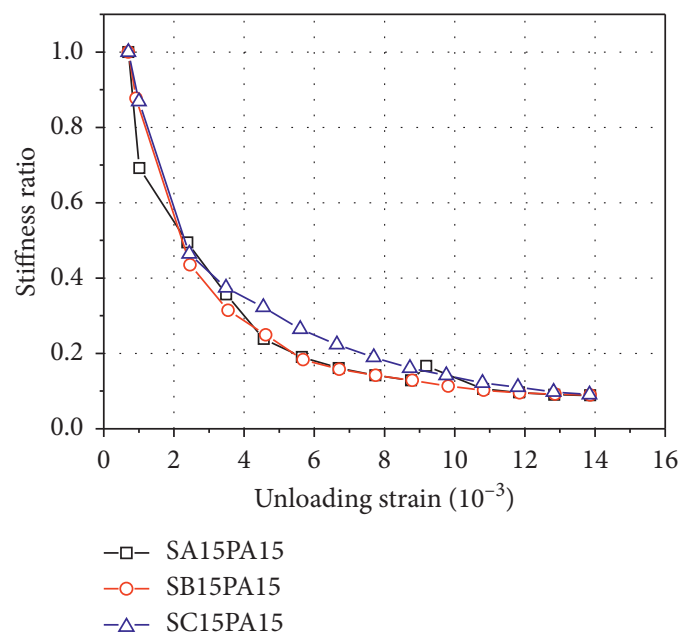

(c)

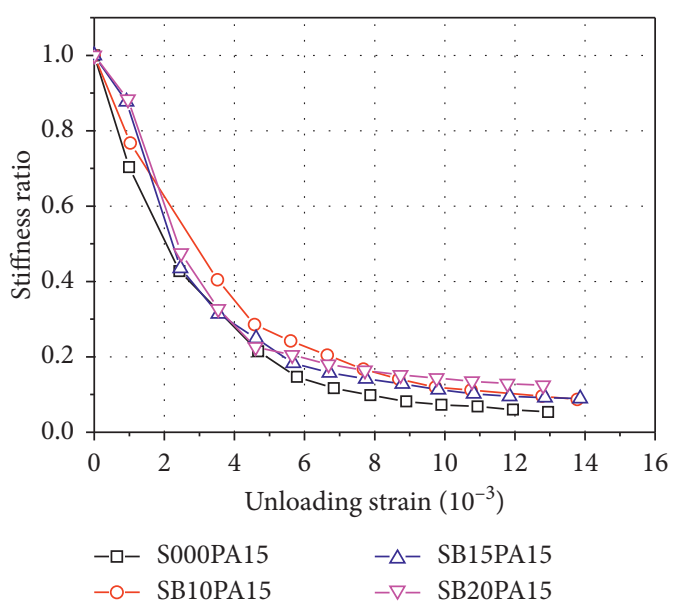

(b)

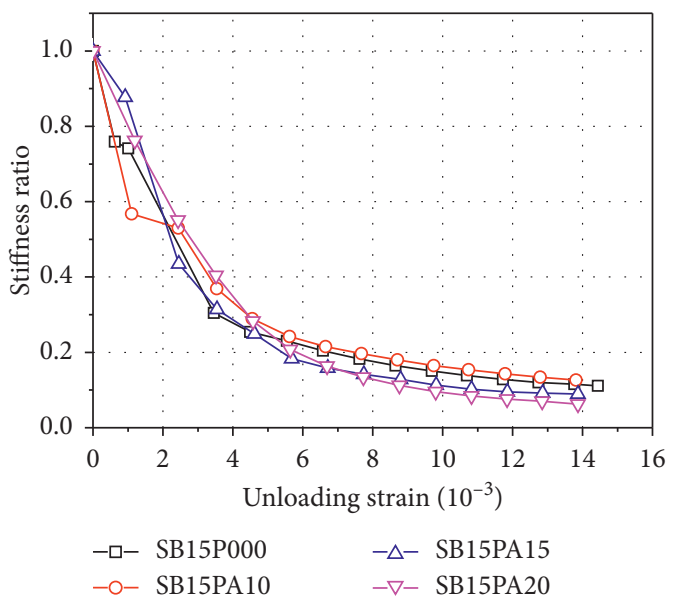

(d)

Figure 8: Unloading stiffness degradation of HFRC under cyclic compression: (a) effect of fiber type; (b) effect of volume fraction of SF; (c) effect of aspect ratio of SF; (d) effect of volume fraction of PF.

and accumulation. Thereafter, the stiffness ratio almost remains a constant until the specimen collapses into failure.

The stiffness degradation of FRC is moderate. The stiffness ratios of FRC are larger than those of plain concrete. A sharp drop in the stiffness ratio of plain concrete is observed when the load reaches the peak strength, while that of FRC specimen is smoother. The results indicate that fibers can effectively alleviate the speed of stiffness degradation process, especially for SF. Moreover, an increase in the volume fraction of SF induces an increase in the stiffness ratio, while an opposite trend is seen as the volume fraction of PF increases. In terms of fiber aspect ratio, the influence on the stiffness degradation is insignificant.

3.2.2. Under Tension. The stiffness degradation process of HFRC under cyclic tension is shown in Figure 9. It is seen that likewise under compression, the stiffness degradation process can be divided into three stages. At the prepeak stage, a very slight degradation or no degradation in the stiffness is observed. The concrete specimen at this interval is almost elastic before the peak stress, and therefore, the plastic strain is near to zero. The unloading path is tracing together with the reloading path. There is no energy dissipated in this stage. However, at the peak stress, macrocracks are formed and then propagate with increasing loading cycles. At this moment, energy dissipation occurs, with the unloading path not overlapping with the reloading path. The stiffness has a sharp decrease immediately after the formation of the macrocracks. The decreased amount of the stiffness decreases with increasing axial strain. After reaching $2000 \mu \varepsilon$, the stiffness tends to be a constant. At this stage, the damage in specimens has been completely developed, and thereafter, the specimen reaches to failure. Moreover, it is also found that fibers have significantly positive effects on the stiffness degradation process of concrete, which is alleviated by the inclusion of hybrid fiber. An increase in both volume fractions of SF and PF as well as aspect ratio of SF leads to an increase in the unloading stiffness, indicating a slow stiffness degradation process. 


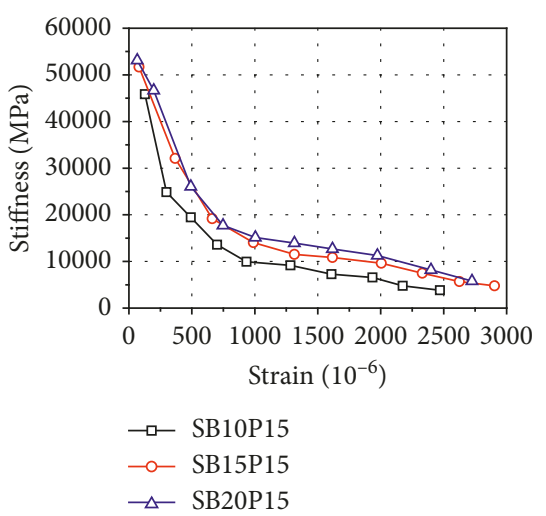

(a)

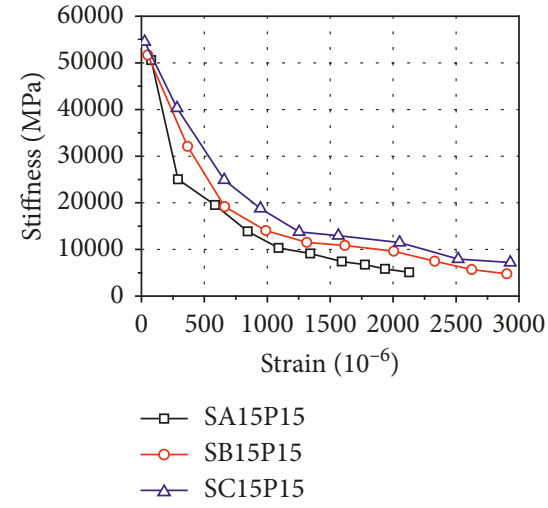

(b)

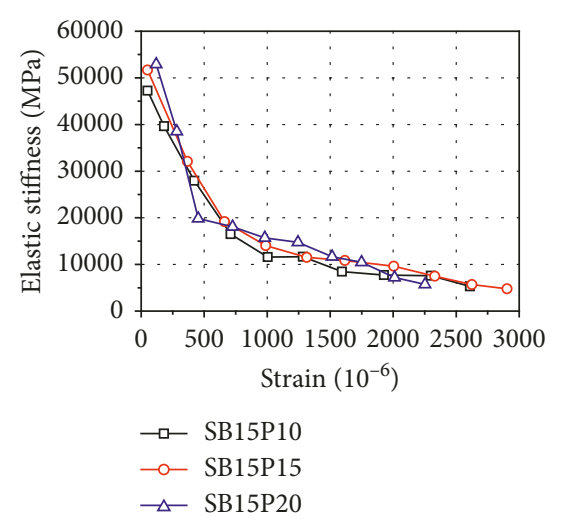

(c)

FIGURE 9: Stiffness degradation process of HFRC under cyclic tension: (a) effect of volume fraction of SF; (b) effect of aspect ratio of SF; (c) effect of volume fraction of PF.

3.3. Cumulative Dissipated Energy. Energy dissipation capacity is usually regarded as a critical index to reflect the seismic performance of specimens subjected to cyclic loadings [48]. Obvious energy dissipation phenomenon during the process of cyclic compression can be observed from Figure 4. Therefore, the cyclic performance of concrete can be analyzed using some parameters related to the mechanism of energy dissipation. In order to evaluate the energy dissipated capacity of HFRC, the dissipated energy $W_{\mathrm{pl}}$ and $\sum W_{\mathrm{pl}}$ are defined [49] and presented in Figure 10 . Herein, $W_{\mathrm{pl}}$ is the area of each loading cycle and $\sum W_{\mathrm{pl}}$ is the cumulative dissipated energy of all the loading cycles.

The dissipated energy $W_{\mathrm{pl}}$ and cumulative dissipated energy $\sum W_{\mathrm{pl}}$ for each loading cycle under compression are shown in Figure 11. It can be seen that all the relationship curves for different concrete mixes are similar and the hybrid fiber mainly affects the postpeak branch of the stress-strain curve. The dissipated energy increases first to the maximum value and then decreases gradually. At the first four loading cycles, the curves are almost the same for variable fiber parameters. After that, the curve changes for variable fiber parameters. Moreover, it is found that the larger fiber volume fraction of SF and PF as well as aspect ratio of SF leads to a stronger energy dissipated capacity of concrete due to the fiber crack-bridging effect.

It should be noted that due to the small hysteretic loop between the reloading and unloading paths and the low energy dissipated capacity of concrete under cyclic tension, the energy dissipation capacity of HFRC is not evaluated and discussed in this study.

3.4. Damage Evolution. As previously discussed, significant stiffness degradation is observed for HFRC under both cyclic compression and tension, which is induced by the damage accumulation during the loading process. Therefore, the damage evolution law can be characterized by the stiffness degradation process of HFRC. In this study, a scalar damage index is introduced and expressed as follows:

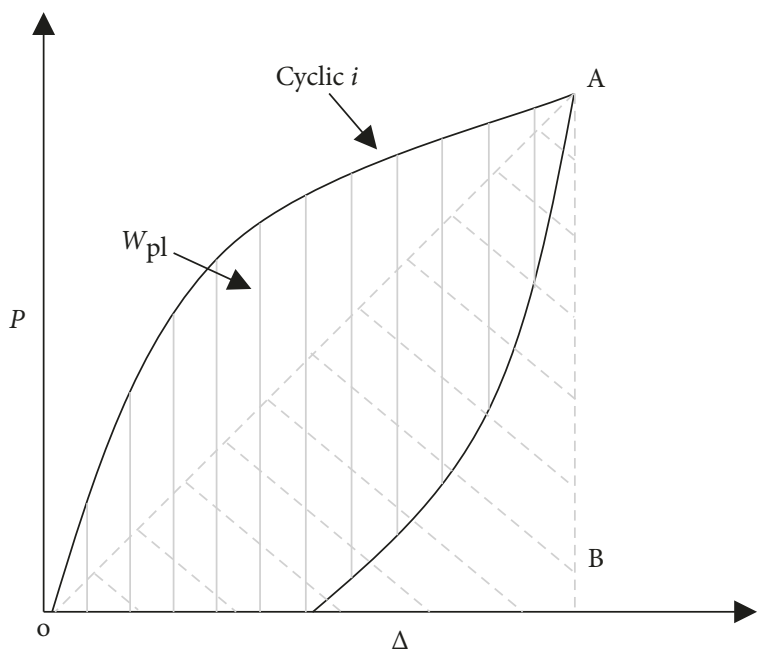

FIgure 10: Definition of the dissipated energy $W_{\mathrm{pl}}$.

$$
d=1-\frac{E_{\text {unl }}}{E_{0}},
$$

where $d$ is the damage index. The value of it ranges from 0 to 1.0. The value 0 represents that there is no damage in concrete, and the value 1.0 indicates that the concrete has been completely damaged. $E_{\text {unl }}$ is the unloading stiffness and $E_{0}$ is the initial elastic modulus.

It has to be mentioned that lots of analytical formulae are proposed to quantify the damage evolution law of concrete. Moreover, it is noted from Figures 8 and 9 that the damage almost remains zero when the specimen is elastic. Therefore, the damage evolution equation should be divided into two segments and there exists a threshold value. In this work, based on a regression analysis of the test results, the following equation is adopted, which is described as

$$
d= \begin{cases}0, & \varepsilon \leq \varepsilon_{\mathrm{th}}, \\ a+b e^{-c \varepsilon}, & \varepsilon>\varepsilon_{\mathrm{th}},\end{cases}
$$

where $d$ is the damage variable; $\varepsilon$ is the strain; $\varepsilon_{\text {th }}$ is the threshold value; and $a, b$, and $c$ are the parameters of the 


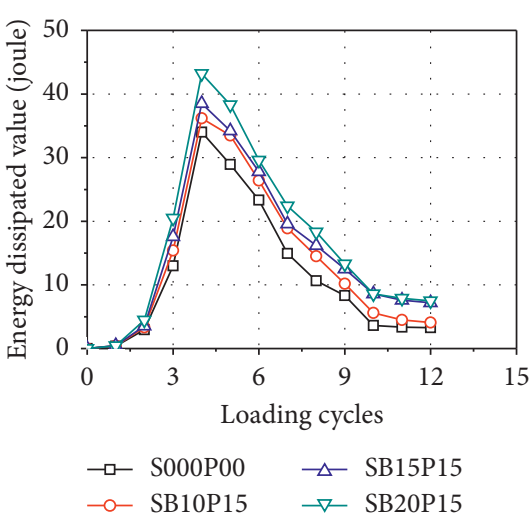

(a)

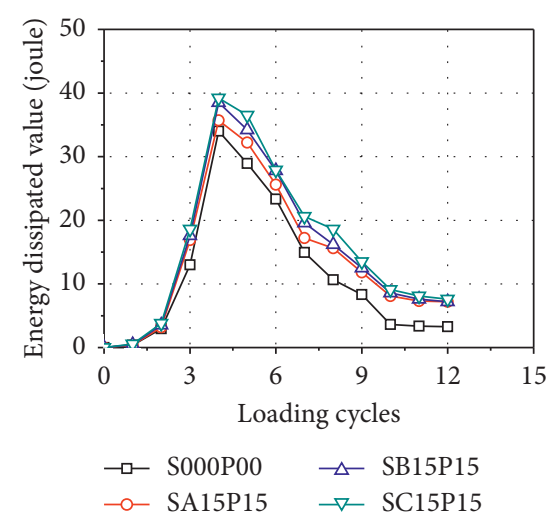

(b)

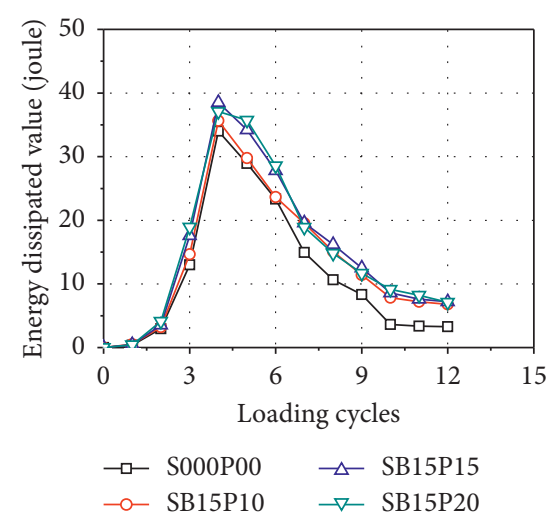

(c)

FIGURE 11: The dissipated energy $W_{\text {pl }}$. (a) Effect of volume fraction of SF. (b) Effect of fiber aspect ratio of SF. (c) Effect of volume fraction of PF.

equation. Using the suggested equation, the fitting results of the damage evolution curves of HFRC for different fiber parameters are shown Figures 12 and 13. The fitting parameters are summarized in Table 4.

3.4.1. Compressive Damage Index. It has been well known that the mechanical response of FRC is closely related to the fiber reinforcing index $\lambda_{\mathrm{f}}$ which is defined as the product of fiber volume fraction and aspect ratio [14-20] and is written as

$$
\lambda_{\mathrm{f}}=V_{\mathrm{f}} \frac{l_{\mathrm{f}}}{d_{\mathrm{f}}},
$$

where $\lambda_{\mathrm{f}}$ is the fiber reinforcing index and $V_{\mathrm{f}}$ and $l_{\mathrm{f}} / d_{\mathrm{f}}$ are the volume fraction and aspect ratio of a fiber, respectively.

It can be seen from Table 4 that the parameters $a$ and $b$ are almost the same for specimens with different fiber parameters. In this study, for a simplified method, the two parameters are assumed as a constant. The average values of them are 0.942 and 1.0, respectively. Moreover, neglecting the synergetic effects of SF and PF, the effective contributions of them are only numerically superimposed, and based on a regression analysis, the parameter $c$ is obtained as

$$
c=0.5\left(0.2517 \lambda_{\mathrm{sf}}+0.3 \lambda_{\mathrm{pf}}-1\right) \text {. }
$$

Therefore, the compressive damage index can be written in equation (6), and the fitting result is shown in Figure 14.

$$
d_{\mathrm{c}}= \begin{cases}0, & \varepsilon_{\mathrm{c}} \leq \varepsilon_{\mathrm{cO}}, \\ 0.942-e^{0.5\left(0.2517 \lambda_{\mathrm{sf}}+0.3 \lambda_{\mathrm{pf}}-1\right) \varepsilon_{\mathrm{c}},} & \varepsilon_{\mathrm{c}}>\varepsilon_{\mathrm{co}},\end{cases}
$$

where $\varepsilon_{\mathrm{co}}$ is the elastic limit of the compressive strain, which is defined as the strain where the stress is $30 \%$ of the peak strength of HFRC.

3.4.2. Tensile Damage Index. It is found from Figure 9 that the effect of PF on the damage evolution of HFRC is insignificant accounted that PF mainly affects the prepeak stage of the stress-strain curves of concrete. Therefore, in the establishment of damage evolution formulae, the effects of $\mathrm{PF}$ are neglected. Based on the test results, the parameters of equation (5) under cyclic tension are determined in equations (7) (9) using a linear function, with the fitting standard deviations of $0.976,0.996$, and 0.999 , respectively. The fitting results are shown in Figure 15.

$$
\begin{aligned}
& a=1.0-0.226 \lambda_{\mathrm{sf}}, \\
& b=-1.0+0.238 \lambda_{\mathrm{sf}}, \\
& c=0.001+0.242 e^{-10 \lambda_{\mathrm{sf}}} .
\end{aligned}
$$

\section{Constitutive Model for HFRC}

\subsection{Concrete Damaged Plasticity Model (CDPM)}

4.1.1. General. From the current study, it is found that the damage and plastic strain are observed significantly when the specimens are subjected to uniaxial cyclic loadings, for both compression and tension. Therefore, in order to precisely predict the behavior of HFRC structures subjected to external loads, the two aspects of damage and plastic strain should be considered. In this study, the concrete damaged plasticity (CDP) model is adopted and then modified by experimental results in the current study and literature in an attempt to predict the responses of HFRC materials and structural members. The CDP model includes four major parts, namely, damage evolution, yield surface, hardening/ softening rules, and flow law.

The CDP model obeys the classical theory of plasticity with the following assumptions:

(1) Additive strain rate decomposition:

$$
\dot{\varepsilon}=\dot{\varepsilon}_{\mathrm{e}}+\dot{\varepsilon}_{\mathrm{p}}
$$

where $\dot{\varepsilon}$ is the strain rate; $\dot{\varepsilon}_{\mathrm{e}}$ is the elastic strain rate; and $\dot{\varepsilon}_{\mathrm{p}}$ is the plastic strain rate.

(2) Scalar damage factor $d$ entering the elasticity stressstrain relation:

$$
\sigma=(1-d) D_{0}^{\mathrm{el}}:\left(\varepsilon-\varepsilon_{\mathrm{p}}\right),
$$




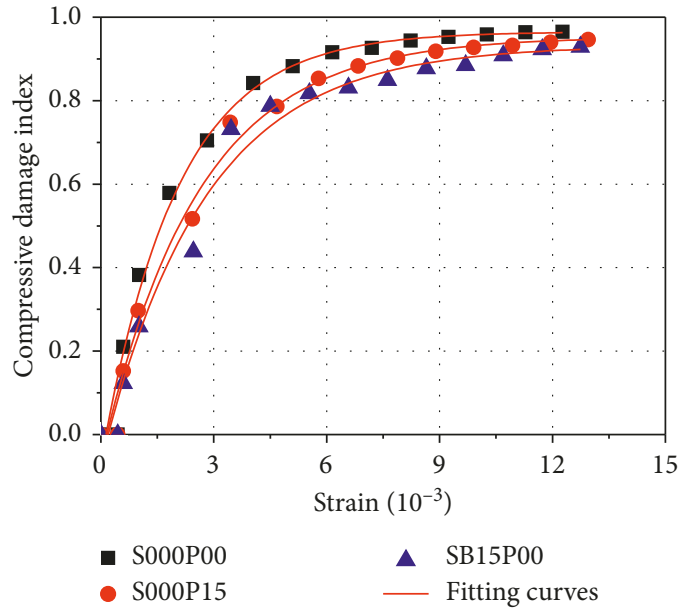

(a)

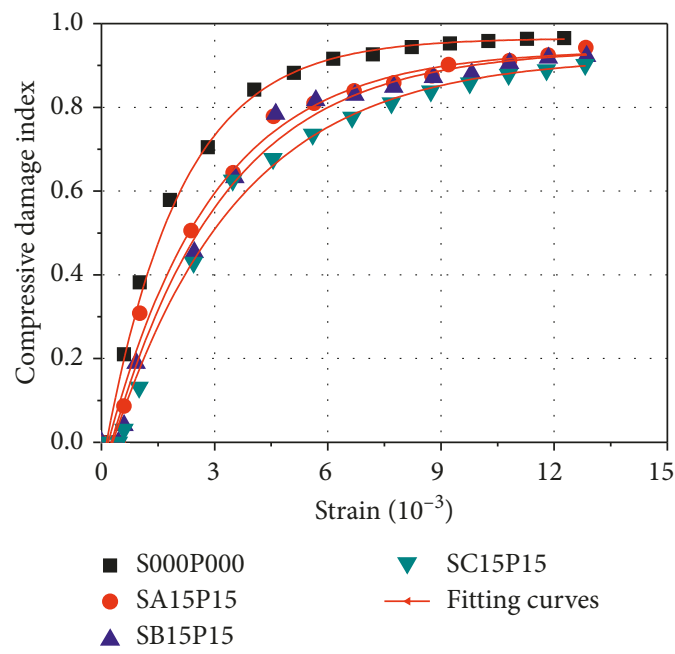

(c)

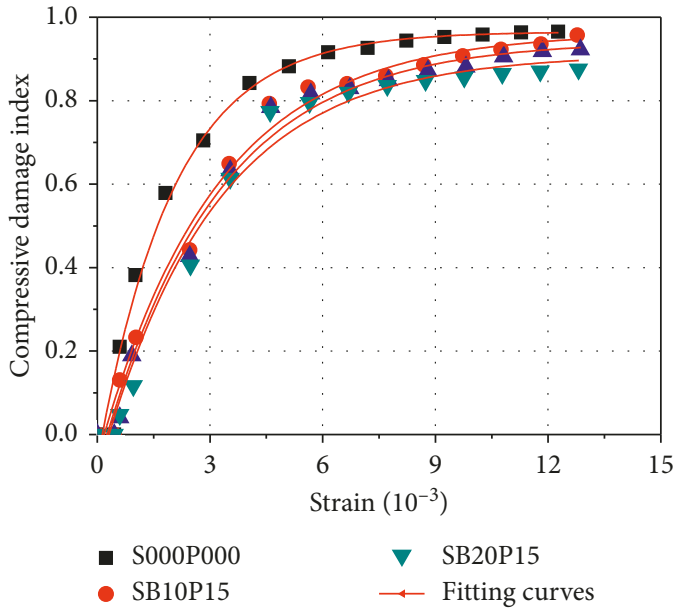

(b)

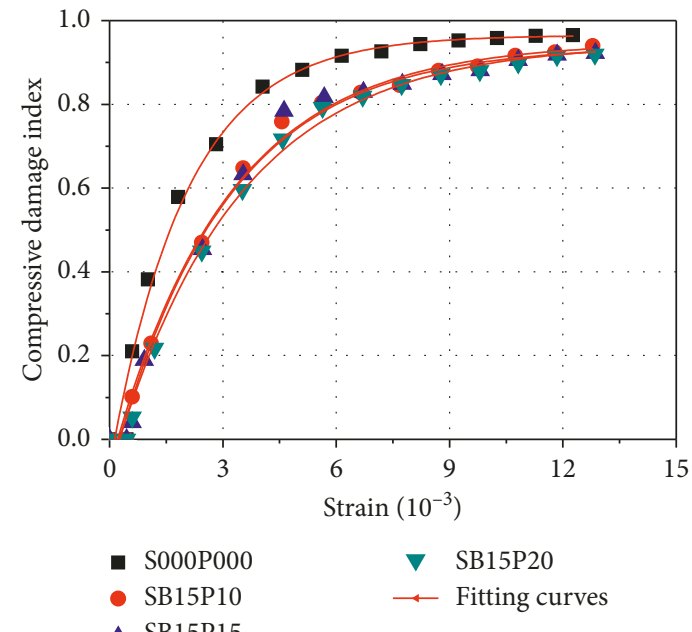

(d)

Figure 12: Damage evolution process of HFRC and fitting results under cyclic compression: (a) effect of fiber type; (b) effect of volume fraction of SF; (c) effect of aspect ratio of SF; (d) effect of volume fraction of PF.

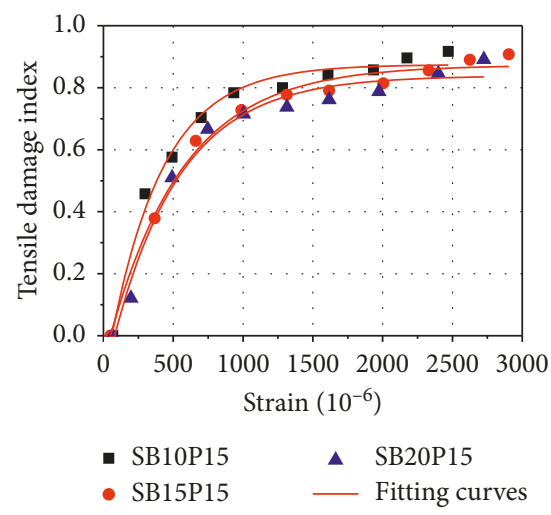

(a)

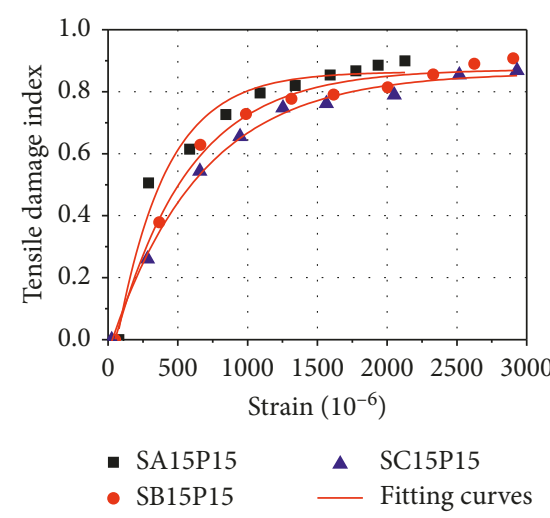

(b)

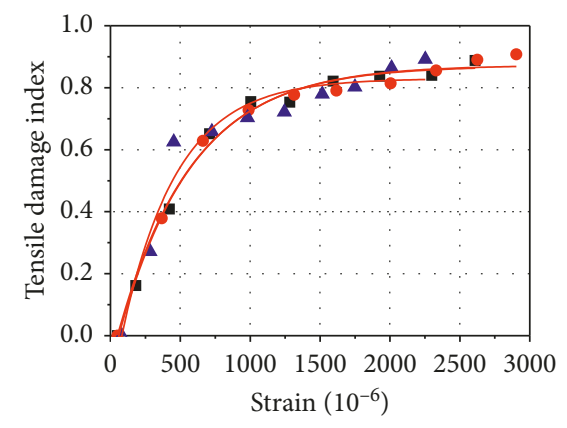

- SB15P10

- SB15P20

- SB15P15 — Fitting curves

(c)

FIGURE 13: Damage evolution laws of SFRC under cyclic tension: (a) effect of fiber volume fraction of SF; (b) effect of fiber aspect ratio of SF; (c) effect of fiber volume fraction of PF. 
TABLE 4: Fitting results of damage evolution laws of HFRC under cyclic compression and tension.

\begin{tabular}{lcccccccrrr}
\hline \multirow{2}{*}{ Specimen } & \multirow{2}{*}{$\lambda_{\mathrm{sf}}$} & $\lambda_{\mathrm{pf}}$ & \multicolumn{4}{c}{ Under compression } & \multicolumn{3}{c}{ Under tension } \\
& & & $a$ & $b$ & $c$ & $R_{\mathrm{c}}^{2}$ & $a$ & $b$ & -1 & - \\
\hline S000P000 & 0 & 0 & 0.965 & 1.033 & 2.007 & 0.945 & 1.0 & -1 & -1 \\
S000PA15 & 0 & 0.25 & 0.953 & 1.014 & 2.376 & 0.993 & 1.0 & -1 & - \\
SB15P000 & 0.9 & 0 & 0.932 & 1 & 2.74 & 0.987 & 0.871 & -0.961 & 0.0019 & 0.996 \\
SB10PA15 & 0.6 & 0.25 & 0.964 & 1.024 & 3.1 & 0.958 & 0.875 & -1.025 & 0.0026 & 0.986 \\
SA15PA15 & 0.6 & 0.25 & 0.937 & 0.999 & 2.799 & 0.979 & 0.884 & -1.033 & 0.0028 & 0.966 \\
SB15PA10 & 0.9 & 0.17 & 0.947 & 1.016 & 3.079 & 0.968 & 0.870 & -0.974 & 0.0019 & 0.992 \\
SB15PA15 & 0.9 & 0.25 & 0.943 & 1.028 & 3.08 & 0.954 & 0.873 & -0.959 & 0.0019 & 0.989 \\
SB15PA20 & 0.9 & 0.33 & 0.947 & 1.024 & 3.317 & 0.965 & 0.868 & -0.956 & 0.0020 & 0.945 \\
SB20PA15 & 1.2 & 0.25 & 0.911 & 1.01 & 3.439 & 0.976 & 0.858 & -0.930 & 0.0016 & 0.979 \\
SC15PA15 & 1.2 & 0.25 & 0.921 & 1.006 & 3.359 & 0.998 & 0.862 & -0.903 & 0.0015 & 0.995 \\
\hline
\end{tabular}

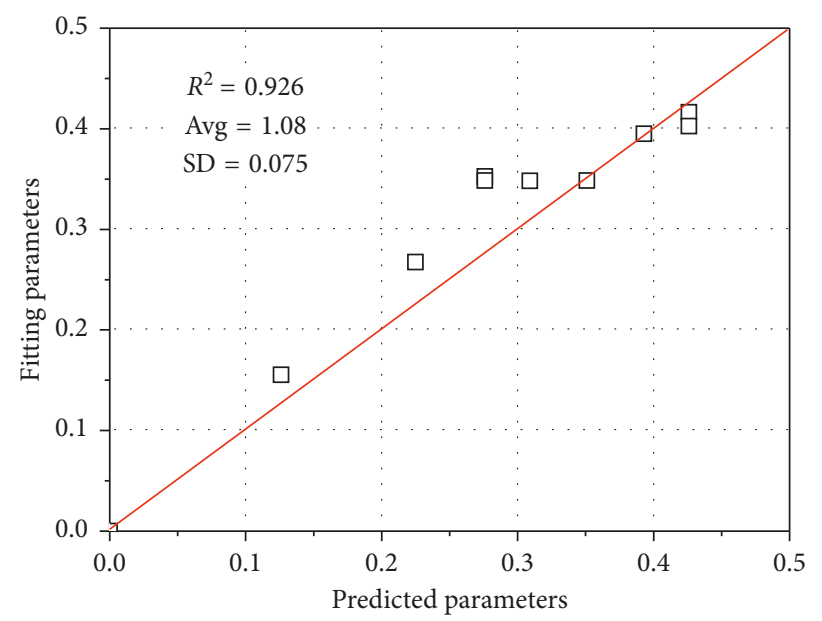

Figure 14: Fitting results of parameter $c$.

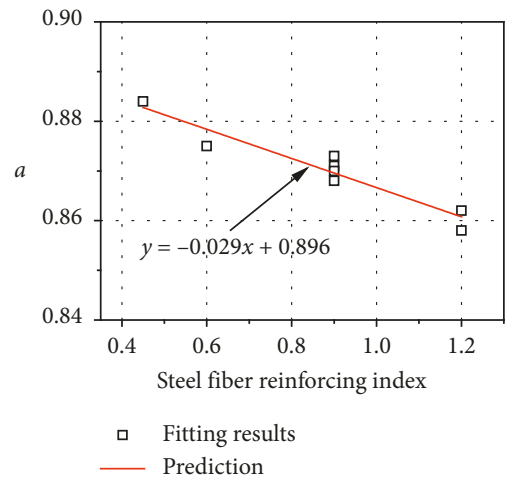

(a)

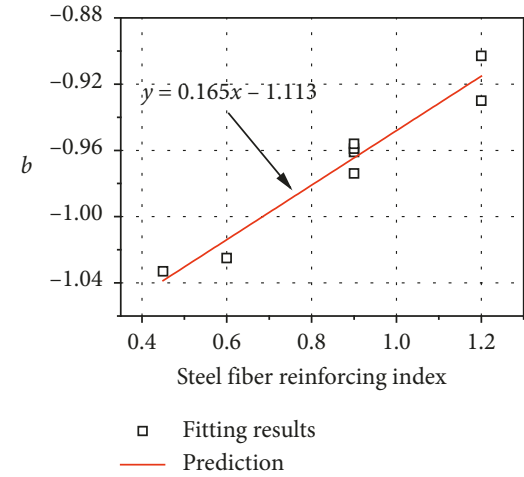

(b)

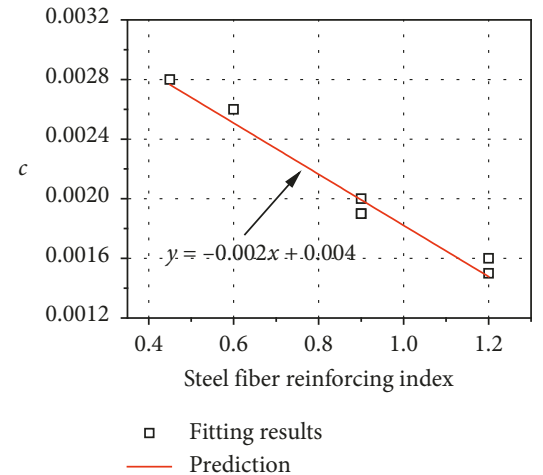

(c)

FIGURE 15: Fitting results of parameters of tensile damage evolution laws: (a) parameter $a$; (b) parameter $b$; (c) parameter $c$.

where $d$ is the scalar damage index; $D_{0}^{\mathrm{el}}$ is the elastic modulus of concrete materials; $\varepsilon$ is the total strain; $\varepsilon_{\mathrm{p}}$ is the plastic strain; and : indicates Frobenius inner product.

(3) Yield function $f\left(\bar{\sigma}, \bar{\varepsilon}^{\mathrm{p}}\right) \leq 0$ obeying Kuhn-Tucker condition:

$$
\dot{\lambda} f=0, \quad \dot{\lambda} \geq 0, \quad f \leq 0,
$$

where $f$ is the yield function and $\lambda$ is the plastic flow multiplier.

(4) Nonassociated potential flow rule:

$$
\dot{\varepsilon}^{\mathrm{p}}=\dot{\lambda} \frac{\partial G(\bar{\sigma})}{\partial \bar{\sigma}}
$$

where $G$ is the plastic potential function and $\bar{\sigma}$ is the effective stress. 
4.1.2. Damage. In the CDP model, a scalar damage index is introduced. The effective stress and Cauchy stress can be transferred using the following equations:

$$
\begin{aligned}
& \bar{\sigma}_{i j}=D_{i j k l}^{\mathrm{el}}\left(\varepsilon_{i j}-\varepsilon_{i j}^{\mathrm{pl}}\right), \\
& \sigma_{i j}=(1-d) \bar{\sigma}_{i j},
\end{aligned}
$$

where $\sigma_{i j}$ is the Cauchy stress tensor; $\bar{\sigma}_{i j}$ is the effective stress tensor; $D_{i j k l}^{\mathrm{el}}$ is the elastic stiffness tensor; $\varepsilon_{i j}$ is the strain tensor; $\varepsilon_{i j}^{\mathrm{pl}}$ is the plastic strain tensor; and $d$ is the damage index, which is associated with the compressive damage index $d_{c}$ and tensile damage index $d_{\mathrm{t}}$.

Specially, the constitutive model of concrete under uniaxial monotonic compression and tension can be written as equations (15) and (16). The schemes of them are shown in Figures 16(a) and 16(b).

$$
\begin{aligned}
& \sigma_{\mathrm{c}}=\left(1-d_{\mathrm{c}}\right) E_{0}\left(\varepsilon_{\mathrm{c}}-\varepsilon_{\mathrm{c}}^{\mathrm{pl}}\right), \\
& \sigma_{\mathrm{t}}=\left(1-d_{\mathrm{t}}\right) E_{0}\left(\varepsilon_{\mathrm{t}}-\varepsilon_{\mathrm{t}}^{\mathrm{pl}}\right),
\end{aligned}
$$

where $\sigma_{\mathrm{c}}$ and $\sigma_{\mathrm{t}}$ are the uniaxial stress under compression and tension respectively and $E_{0}$ is the elastic modulus of concrete materials.

While under cyclic loading conditions, the damage index can be given as

$$
d=1-\left(1-s_{\mathrm{t}} d_{\mathrm{c}}\right)\left(1-s_{\mathrm{c}} d_{\mathrm{t}}\right)
$$

where $s_{\mathrm{t}}$ and $s_{\mathrm{c}}$ are the dimensionless coefficients accounting for the stress state and stiffness recovery effects.

$$
\begin{aligned}
& s_{\mathrm{t}}=1-w_{\mathrm{t}} r^{*}\left(\sigma_{11}\right), \quad 0 \leq \omega_{\mathrm{t}} \leq 1, \\
& s_{\mathrm{c}}=1-w_{\mathrm{c}}\left(1-r^{*}\left(\sigma_{11}\right)\right), \quad 0 \leq \omega_{\mathrm{c}} \leq 1,
\end{aligned}
$$

where $w_{\mathrm{t}}$ and $w_{\mathrm{c}}$ are the weighting factors ranging from 0 to 1. The factor $w_{c}$ accounts for the reclosing of cracks after a tension-compression reversal; $w_{\mathrm{t}}$ represents the recovery of crushed concrete after a compression-tension reversal. In ABAQUS, the default values of them are 1.0 and 0 . In this study, $w_{\mathrm{c}}=0.9$ and $w_{\mathrm{t}}=0$ are assumed, which means that $90 \%$ of the cracks close upon the tension-compression reversal, and the crushed concrete does not experience any recovery. $\sigma_{11}$ is the first principle uniaxial stress (positive for tension). $r^{*}$ is a stress state parameter and given as

$$
r^{*}\left(\sigma_{11}\right)=H\left(\sigma_{11}\right)= \begin{cases}1, & \sigma_{11}>0, \\ 0, & \sigma_{11}<0 .\end{cases}
$$

For a better understanding of the effect of $s_{\mathrm{c}}$ and $s_{\mathrm{t}}$ coefficients, the uniaxial stress-strain loading-unloading behavior is schematically illustrated in Figure 16(c) [50].

4.1.3. Yield Surface. The classical Drucker-Prager yield surface is modified by two independent parameters and two sets of data, as shown in Figure 17 [51]. The data sets are the uniaxial stress-strain relationship independent in tension and compression. The first parameter is the ratio of the biaxial compressive yield stress $\sigma_{\mathrm{b} 0}$ to the uniaxial yield stress $\sigma_{\mathrm{c} 0}$, adapting the yield surface in a biaxial stress state. The second parameter
$K_{\mathrm{c}}$ changes the shape of deviatoric plane from its circular shape into a smooth triangular shape, as shown in Figure 18.

The yield function in ABAQUS is proposed by Lubliner et al. [52] and then modified by Lee and Fenves [53]. In terms of the effective stress, the yield function is expressed as

$$
\begin{aligned}
F= & \frac{1}{1-\alpha}\left(\bar{q}-3 \alpha \bar{p}+\beta\left(\widetilde{\mathcal{\varepsilon}}^{\mathrm{p}}\right)\left\langle\hat{\bar{\sigma}}_{\max }\right\rangle-\gamma\left\langle-\hat{\bar{\sigma}}_{\max }\right\rangle\right) \\
& -\bar{\sigma}_{\mathrm{c}}\left(\widetilde{\mathcal{\varepsilon}}^{\mathrm{p}}\right) \leq 0, \\
\alpha= & \frac{\left(\sigma_{\mathrm{b} 0} / \sigma_{\mathrm{c} 0}\right)-1}{2\left(\sigma_{\mathrm{b} 0} / \sigma_{\mathrm{c} 0}\right)-1}, \\
\beta\left(\widetilde{\mathcal{\varepsilon}}_{\mathrm{c}}^{\mathrm{p}}\right)= & \frac{\bar{\sigma}_{\mathrm{c} 0}\left(\widetilde{\varepsilon}_{\mathrm{c}}^{\mathrm{p}}\right)}{\bar{\sigma}_{\mathrm{t} 0}\left(\widetilde{\varepsilon}_{\mathrm{c}}^{\mathrm{p}}\right)}(1-\alpha)-(1+\alpha), \\
\gamma= & \frac{3\left(1-K_{\mathrm{c}}\right)}{2 K_{\mathrm{c}}-1}, \\
K_{\mathrm{c}}= & \frac{\bar{q}_{\mathrm{TM}}}{\bar{q}_{\mathrm{CM}}}
\end{aligned}
$$

where $\bar{p}=-(1 / 3) \bar{\sigma}: I$ is the effective hydrostatic pressure; $\bar{q}=\sqrt{(2 / 3) \bar{S}: \bar{S}}$ is the equivalent von Mises stress; $\bar{S}=\bar{\sigma}+$ $\bar{p} I$ is the deviator of the effective stress; $\langle\cdot\rangle$ is the Macaulay bracket, $\langle x\rangle=(1 / 2)(x+|x|) ; \bar{\sigma}_{\max }$ is the maximum eigenvalue of tensor $\bar{\sigma}$; $\alpha$ and $\gamma$ are the dimensionless parameters of the material; and the function $\beta\left(\widetilde{\varepsilon}_{\mathrm{c}}^{\mathrm{p}}\right)$ is given by equation (22). $\bar{\sigma}_{\mathrm{c} 0}$ and $\bar{\sigma}_{\mathrm{t} 0}$ are the compressive and tensile effective cohesion stress. $\bar{\sigma}_{\mathrm{c} 0} / \bar{\sigma}_{\mathrm{t} 0}$ represents the ratio of the initial equibiaxial compressive yield stress to the initial uniaxial compressive yield stress. $K_{c}$ is the ratio of the second stress invariant on the tensile meridian $\bar{q}_{\mathrm{TM}}$ at the initial yield for any given pressure invariant $p$ and the compressive meridian $\bar{q}_{\mathrm{CM}}$, and compulsively the condition $0.5<K_{\mathrm{c}} \leq 1.0$ must be satisfied.

4.1.4. Hardening/Softening Rule. The hardening/softening rules are of critical importance to control the shape and location of the loading surface, as well as the evolution after the initial yield. In ABAQUS, an isotropic hardening rule which is driven to the equivalent plastic strain can be changed by the inelastic strain (for compression) and crack strain (for tension), as illustrated in Figure 19. The calculation methods of the plastic strain and inelastic strain are given as

$$
\begin{gathered}
\widetilde{\mathcal{\varepsilon}}_{\mathrm{t}}^{\mathrm{ck}}=\frac{\varepsilon_{\mathrm{t}}-\sigma_{\mathrm{t}}}{E_{0}}, \\
\widetilde{\mathcal{E}}_{\mathrm{c}}^{\mathrm{in}}=\frac{\mathcal{E}_{\mathrm{c}}-\sigma_{\mathrm{c}}}{E_{0}},
\end{gathered}
$$

where $\widetilde{\varepsilon}_{\mathrm{t}}^{\mathrm{ck}}$ and $\widetilde{\varepsilon}_{\mathrm{c}}^{\text {in }}$ are the tensile crack strain and compressive inelastic strain. The equivalent plastic strain which is associated to the damage and current stress can be calculated by the following equations: 


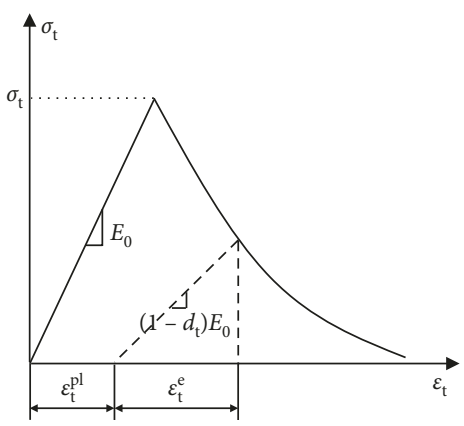

(a)

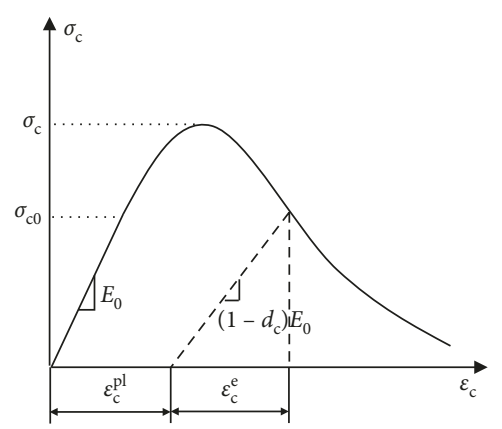

(b)

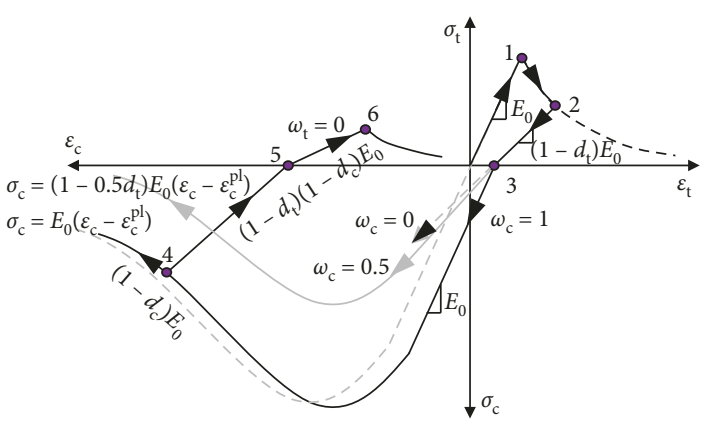

(c)

FIGURE 16: Stress-strain relationships of the CDP model in ABAQUS: (a) compressive curve; (b) tensile curve; (c) uniaxial load cycle (tension-compression-tension) response considering different values for the stiffness recovery factors.

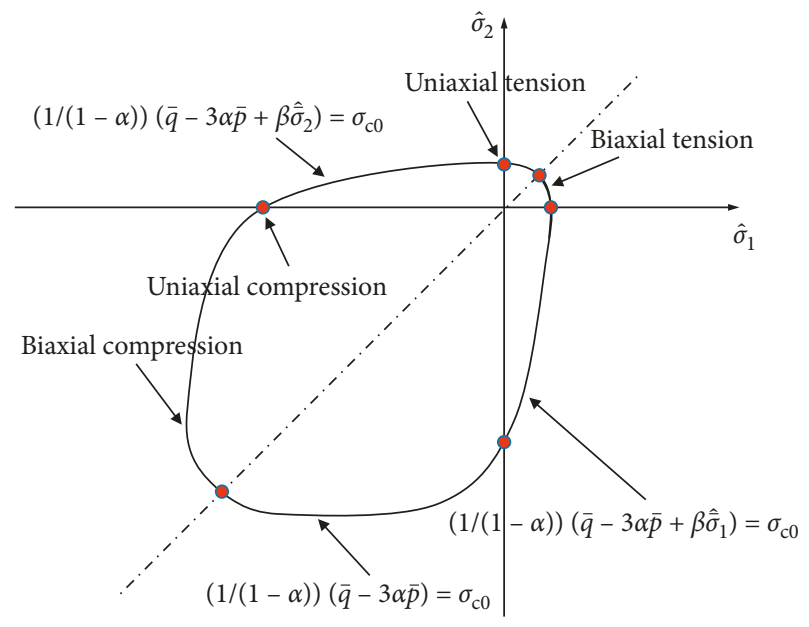

Figure 17: Yield surface in plane stress state [51].

$$
\begin{aligned}
& \widetilde{\varepsilon}_{\mathrm{t}}^{\mathrm{pl}}=\widetilde{\varepsilon}_{\mathrm{t}}^{\mathrm{ck}}-\frac{d_{\mathrm{t}}}{1-d_{\mathrm{t}}} \frac{\sigma_{\mathrm{t}}}{E_{0}}, \\
& \widetilde{\varepsilon}_{\mathrm{c}}^{\mathrm{pl}}=\widetilde{\mathcal{\varepsilon}}_{\mathrm{c}}^{\mathrm{in}}-\frac{d_{\mathrm{c}}}{1-d_{\mathrm{c}}} \frac{\sigma_{\mathrm{c}}}{E_{0}},
\end{aligned}
$$

where $\widetilde{\varepsilon}_{t}^{\mathrm{pl}}$ and $\widetilde{\mathcal{E}}_{\mathrm{c}}^{\mathrm{pl}}$ are the plastic strain for tension and compression, respectively.

In ABAQUS, it needs to refer the initial tensile crack strain and limit compressive elastic strain. In this work, the peak strain of tensile stress-strain curve and the strain at $30 \%$ of the peak stress of the compressive stressstrain curve of concrete are used [54], as shown in Figure 18.

4.1.5. Nonassociated Potential Flow. The nonassociated potential flow is adopted in CDP model, which is given as

$$
G=\sqrt{\left(e \sigma_{\mathrm{t} 0} \tan \psi\right)^{2}+\bar{q}^{2}}+\bar{p} \tan \psi,
$$

where $G$ is the potential function; $\psi$ is the dilation angle measured in the $p$ - $q$ plane; $\sigma_{\mathrm{t} 0}$ is the uniaxial tensile stress; and $e$ is the eccentricity of the potential flow which defines the rate where the function approaches the asymptote (the linear

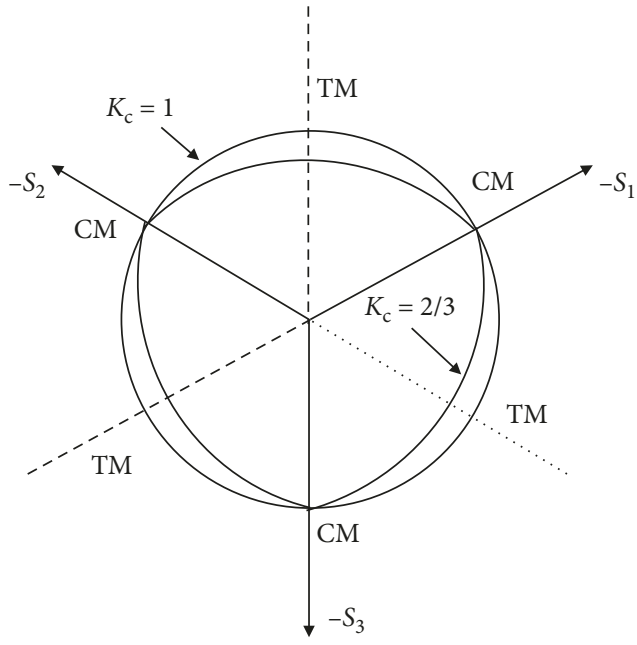

FIgURE 18: Yield surface in deviatoric plane, corresponding to different values of $K_{c}$ [51].

Drucker-Prager flow potential), which can be assumed as 0.1. The above mentioned values are interpreted in Figure 20.

4.2. Parameter Modification. In ABAQUS, only two sets of uniaxial data and five additional controlling parameters are needed to input into the software. The uniaxial data corresponding to the stress-strain behavior (under compression and tension separately) after reaching yielding are calculated by equations (25) and (26). The additional five parameters describe the yield surface, potential flow, and viscoplastic regulation, respectively. The first two parameters are $\bar{\sigma}_{\mathrm{c} 0} / \bar{\sigma}_{\mathrm{t} 0}$ and $K_{c}$ to modify the yield surface. Two other parameters modify the nonassociated potential flow: dilation angle $\psi$ and eccentricity of the potential flow $e$. The last one helps to converge the analysis by assuming the viscosity of the material.

The modification of the five additional parameters for HFRC has been conducted by the authors' previous studies. The details of them can be found in Reference [29]. The parameters are all related to the fiber characteristic indexes of both SF and PF. The formulae are shown as 


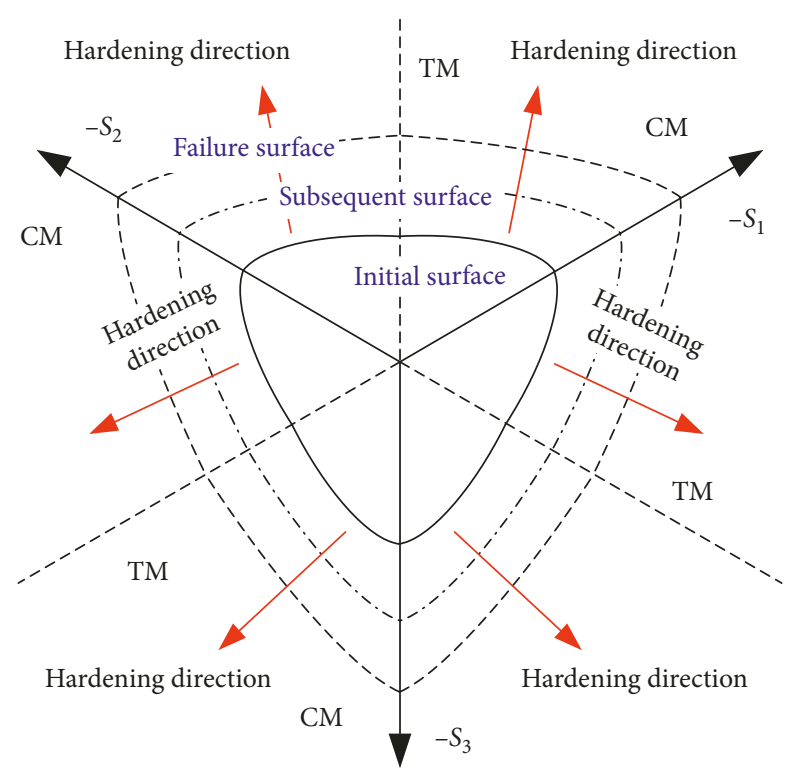

Figure 19: Isotropic hardening in deviatoric plane [51].

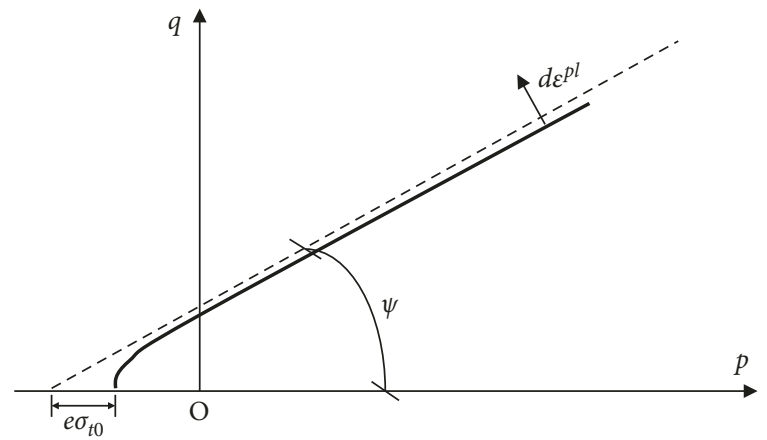

Figure 20: Hyperbolic flow potentials in the meridian plane [51].

$$
\begin{aligned}
K_{\mathrm{hf}} & =\frac{\bar{q}(\mathrm{TM}) \cdot k_{\mathrm{t}}}{\bar{q}(\mathrm{CM}) \cdot k_{\mathrm{c}}}=K_{\mathrm{c}} \cdot \frac{k_{\mathrm{t}}}{k_{\mathrm{c}}}, \\
k_{\mathrm{c}} & =1+0.056 \lambda_{\mathrm{sf}}, \\
k_{\mathrm{t}} & =1+0.08 \lambda_{\mathrm{sf}}+0.132 \lambda_{\mathrm{pf}},
\end{aligned}
$$

where $\lambda_{\mathrm{sf}}=V_{\mathrm{sf}}\left(l_{\mathrm{sf}} / d_{\mathrm{sf}}\right)$ and $\lambda_{\mathrm{pf}}=V_{\mathrm{pf}}\left(l_{\mathrm{pf}} / d_{\mathrm{pf}}\right)$ are the fiber characteristic parameters of SF and PF; $V_{\mathrm{sf}}$ and $V_{\mathrm{pf}}$ are the fiber volume fractions of SF and PF; and $l_{\mathrm{sf}} / d_{\mathrm{sf}}$ and $l_{\mathrm{pf}} / d_{\mathrm{pf}}$ are the aspect ratios of SF and PF, respectively.

$$
\begin{aligned}
\frac{\sigma_{\mathrm{b} 0}^{\mathrm{hf}}}{\sigma_{\mathrm{c} 0}} & \frac{-\left(0.749 /\left(k_{\mathrm{t}}-0.728\right)\right)+\sqrt{\left(0.749 /\left(k_{\mathrm{t}}-0.728\right)\right)^{2}+\left(0.03 / k_{\mathrm{t}}^{2}\right)}}{0.132 / k_{\mathrm{t}}^{2}} .
\end{aligned}
$$

For plain concrete $\left(k_{\mathrm{t}}=1\right), \sigma_{\mathrm{b} 0} / \sigma_{\mathrm{c} 0}=1.16$.

$$
\psi=\psi_{0}\left(1-0.89 \lambda_{\mathrm{sf}}-0.196 \lambda_{\mathrm{pf}}\right) \text {, }
$$

where $\psi_{0}$ is the dilation angle for plain concrete, which is strongly associated to the confinement and concrete strength [55]. In general, increasing confinement results in a higher volumetric and shear strain capacity of concrete, leading to a smaller dilatation angle, while an opposite tendency is observed for the concrete strength [56]. To reflect the above analysis, the empirical formula proposed by Rousakis et al. [57] is adopted:

$$
\psi_{0}=36^{\circ}+1^{\circ}\left[\frac{\sigma_{\mathrm{c} 0}}{3.5 \sigma_{\mathrm{cm} 0}}\right] \text {, }
$$

where $\sigma_{\mathrm{cm} 0}$ is a parameter for equivalence of units and $\sigma_{\mathrm{cm} 0}=$ $10 \mathrm{MPa}$ is recommended [57].

The uniaxial monotonic tensile stress-strain equation for HFRC established by Xu et al. [14] is adopted. The formulae are written as

$$
\begin{aligned}
\sigma_{\mathrm{t}} & =\left(1-d_{\mathrm{t}}\right) E_{\mathrm{ft}} \varepsilon_{\mathrm{t}}, \\
d_{\mathrm{t}} & = \begin{cases}1-\rho_{\mathrm{t}}\left[\alpha_{1}+\left(1.5-1.25 \alpha_{1}\right) x+\left(0.25 \alpha_{1}-0.5\right) x^{5}\right], & x \leq 1, \\
1-\frac{\rho_{t}}{\alpha_{t}(x-1)^{1.7}+x}, & x>1,\end{cases} \\
\alpha_{1} & =1.2\left(1+0.265 \lambda_{\mathrm{sf}}+0.277 \lambda_{\mathrm{pf}}\right), \quad\left(1.2 \leq \alpha_{\mathrm{t}} \leq 2\right), \\
\alpha_{\mathrm{t}} & =\frac{0.312 f_{\mathrm{t}}^{2}}{1+3.366 \lambda_{\mathrm{sf}}+3.858 \lambda_{\mathrm{pf}}}, \quad\left(0 \leq \alpha_{\mathrm{t}} \leq 1.5\right), \\
f_{\mathrm{ft}} & =f_{\mathrm{t}}\left(1+0.379 \lambda_{\mathrm{sf}}+0.02 \lambda_{\mathrm{sf}} \lambda_{\mathrm{pf}}\right), \\
\varepsilon_{\mathrm{ft}} & =\varepsilon_{\mathrm{t}}\left(1+0.498 \lambda_{\mathrm{sf}}+0.697 \lambda_{\mathrm{pf}}\right), \\
x & =\frac{\varepsilon_{\mathrm{t}}}{\varepsilon_{\mathrm{ft}}}, \\
\rho_{\mathrm{t}} & =\frac{f_{\mathrm{t}}}{E_{\mathrm{ft}} \varepsilon_{\mathrm{ft}}},
\end{aligned}
$$


where $f_{\mathrm{ft}}$ and $f_{\mathrm{t}}$ are the peak stress of HFRC and plain concrete, respectively, and $\varepsilon_{\mathrm{ft}}$ and $\varepsilon_{\mathrm{t}}$ are the peak strain of HFRC and plain concrete under uniaxial monotonic tension.

For uniaxial monotonic compression, the equations for stress-strain curves of HFRC proposed by Xu et al. [58] are given as

$$
\begin{aligned}
& \begin{cases}y=a x+(3-2 a) x^{2}+(a-2) x^{3}, & 0 \leq x \leq 1, \\
y=\frac{x}{b(x-1)^{2}+x}, & x>1,\end{cases} \\
& a_{\mathrm{c}}=1.64+0.4772 \lambda_{\mathrm{sf}}-0.4917 \lambda_{\mathrm{pf}}, \quad\left(1.5 \leq a_{\mathrm{c}} \leq 3\right), \\
& b_{\mathrm{c}}=1.185-0.501 \lambda_{\mathrm{sf}}-0.307 \lambda_{\mathrm{pf}}, \\
& f_{\mathrm{cu}}=f_{\mathrm{cu} 0}\left(1+0.179 \lambda_{\mathrm{sf}}+0.341 \lambda_{\mathrm{pf}}\right), \\
& \varepsilon_{\mathrm{c}}=\varepsilon_{\mathrm{c} 0}\left(1+0.55 \lambda_{\mathrm{sf}}+0.303 \lambda_{\mathrm{pf}}\right), \\
& \varepsilon_{\mathrm{fc} 0}=263.3 \sqrt{f_{\mathrm{fc}}} \times 10^{-6}, \\
& x=\frac{\varepsilon_{\mathrm{c}}}{\varepsilon_{\mathrm{fc} 0}} \\
& y=\frac{\sigma_{\mathrm{c}}}{f_{\mathrm{fc}}}
\end{aligned}
$$

where $f_{\mathrm{fc}}$ and $f_{\mathrm{c}}$ are the peak stress of HFRC and plain concrete, respectively, and $\varepsilon_{\mathrm{fc}}$ and $\varepsilon_{\mathrm{c}}$ are the peak strain of HFRC and plain concrete under uniaxial monotonic tension.

\section{Numerical Results}

The model verifications of the damage evolution are upon the concrete material and structural member scales. At the material scale, the established FE model is a unit with a three-dimensional eight-node linear brick and reduced integration with hourglass control solid element (C3D8R). At the member scale, the model is verified for the HFRC deep beam under shear and HFRC beam-column joint under seismic loads. The establishments of the models are in accordance with the experimental program in the literature.

5.1. Material Element. The typical HFRC used in the FE model at the material scale is reinforced with $1.5 \% \mathrm{SF}$ and $0.15 \%$ PF. The aspect ratios of SF and PF are 60 and 167, respectively. The damage index and parameters needed are determined by the equations above and listed in Table 5 . Four distinct loading paths are selected, namely, uniaxial tension, uniaxial compression, triaxial compression, and the cyclic compressive loading path. The results of the model prediction are shown in Figure 21. It is evident that the FE predictions agree well with the theoretical and test results.

\subsection{Structural Member}

5.2.1. HFRC Deep Beam under Shear. Liu and Xu [19] reported the experimental results of the shear behavior of HFRC deep beam. The cross section of the beam is $150 \mathrm{~mm} \times$ $500 \mathrm{~mm}$, and the span length of the beam is $800 \mathrm{~mm}$. The shear span ratio and span-depth ratio are 1.0 and 1.6, respectively. The details of the setup and reinforcement designed are shown in Figure 22. The fiber information is as follows: $V_{\mathrm{sf}}=1.5 \%, l_{\mathrm{sf}} / d_{\mathrm{sf}}=60, V_{\mathrm{pf}}=0.15 \%$, and $l_{\mathrm{pf}} / d_{\mathrm{pf}}=167$. The compressive strength of concrete is $58.6 \mathrm{MPa}$.

In the FE model, the components of steel reinforcement and concrete are separately established. The truss element (T3D2) and solid element (C2D8R) are assigned, respectively. The embedded region constraint is used to simulate the interaction between reinforcement and concrete matrix. Moreover, a steel plate alike as rigid is tied to the top middle of the beam. The established FE model is shown in Figure 23.

In the beam test, the load-controlled method before the peak load and the displacement-controlled method after the peak load were adopted. Specially, the two preloading loads of $100 \mathrm{kN}$ were applied. Before the peak load, the load increment was set as $50 \mathrm{kN}$. After that, the displacementcontrolled method was adopted with a speed of $0.6 \mathrm{~mm} /$ min until the specimen was failure. However, in the FE simulation, the displacement-controlled load applied to the reference point was used with the speed of $0.001 \mathrm{~mm} / \mathrm{s}$ during the whole loading process.

Figures 24 and 25 compare the numerical results with the experimental results in Reference [19] with respect to the failure mode and axial load-axial displacement curve, respectively. The cloud diagram of the maximum principle plastic strain of concrete can be used to reflect the position and orientation of the cracks. The results indicate that the failure of the reinforced concrete (RC) deep beam is the splitting failure mainly induced by the shear diagonal cracks. The cracking of concrete is mainly due to the maximum tensile stress at the bottom of the specimen. The widths and lengths of the cracks increase with increasing external loads. During the loading process, the internal stress redistribution in the specimen forms the shear oblique cracks on the specimen surface like an arch. Moreover, the prediction of the load-deflection curves agrees well with the testing curves. It can be concluded that the modified CDP model can provide a close estimation of the shear behavior of HFRC deep beam, in terms of the cracking process, ultimate bearing capacity, and deformation.

\subsubsection{HFRC Beam-Column Joints under Seismic Loading.} The authors conducted an experimental investigation on the seismic performance of HFRC beam-column joints. The details of the dimensions and design of reinforcement steel bars are shown in Figure 26. In this work, the specimen $\left(V_{\mathrm{sf}}=1.5 \%, l_{\mathrm{sf}} / d_{\mathrm{sf}}=60, V_{\mathrm{pf}}=0.15 \%, l_{\mathrm{pf}} / d_{\mathrm{pf}}=167\right.$, and $f_{\mathrm{c}}=$ $60.5 \mathrm{MPa}$ ) is selected, and the five additional parameters used are shown in Table 5. The axial load limit used in the beam-column joint was $457 \mathrm{kN}$. The steel reinforcement and 
TABLE 5: Model parameters used in the model verification for SB15PA15.

\begin{tabular}{ccccccccccccc}
\hline \multicolumn{3}{c}{ Under compression } & \multicolumn{3}{c}{ Under tension } & \multicolumn{3}{c}{ Material constant } & \multicolumn{4}{c}{ Five additional parameters } \\
$a_{\mathrm{c}}$ & $b_{\mathrm{c}}$ & $f_{\mathrm{c}}(\mathrm{MPa})$ & $a_{\mathrm{t}}$ & $b_{\mathrm{t}}$ & $f_{\mathrm{t}}(\mathrm{MPa})$ & $E_{0}(\mathrm{MPa})$ & $v$ & $\sigma_{\mathrm{b} 0}^{\mathrm{hf}} / \sigma_{\mathrm{c} 0}^{\mathrm{hf}}$ & $K_{\mathrm{c}}$ & $\psi\left({ }^{\circ}\right)$ & $e$ & $\mu$ \\
\hline 1.64 & 1.185 & 42 & 1.2 & 1.185 & 5.2 & $3.2 \times 10^{4}$ & 0.2 & 1.987 & 0.701 & 15 & 0.1 & 0.0005 \\
\hline
\end{tabular}

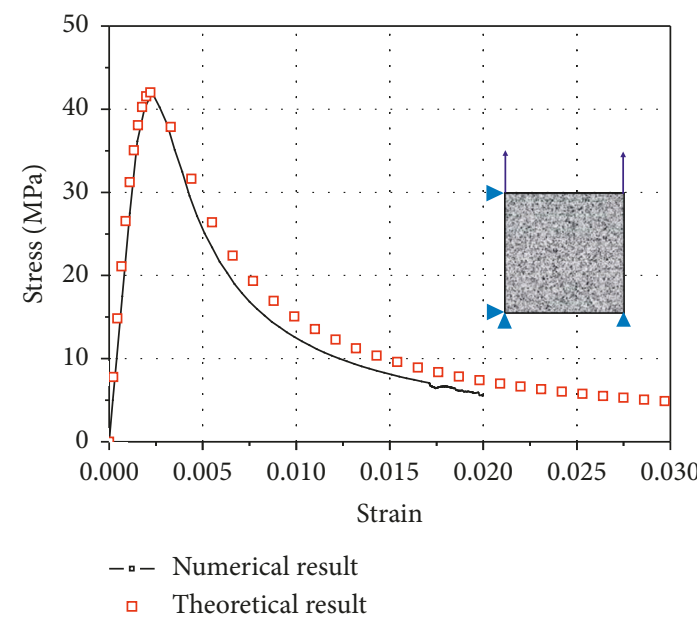

(a)

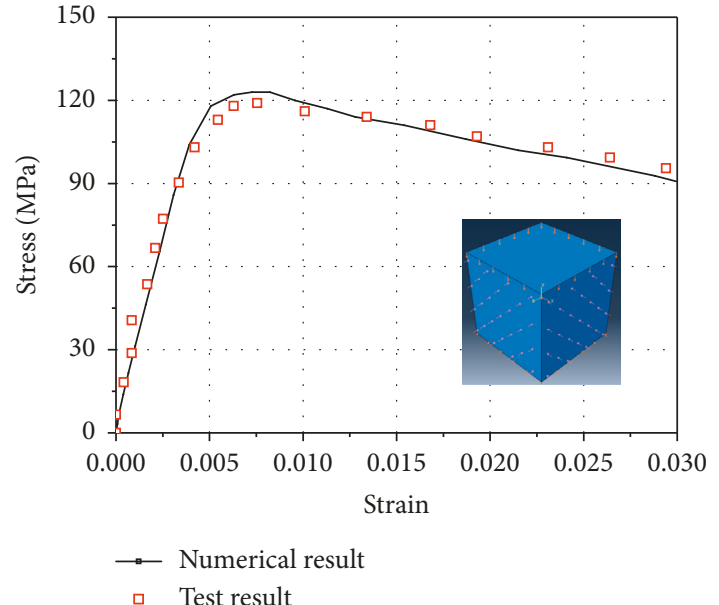

(c)

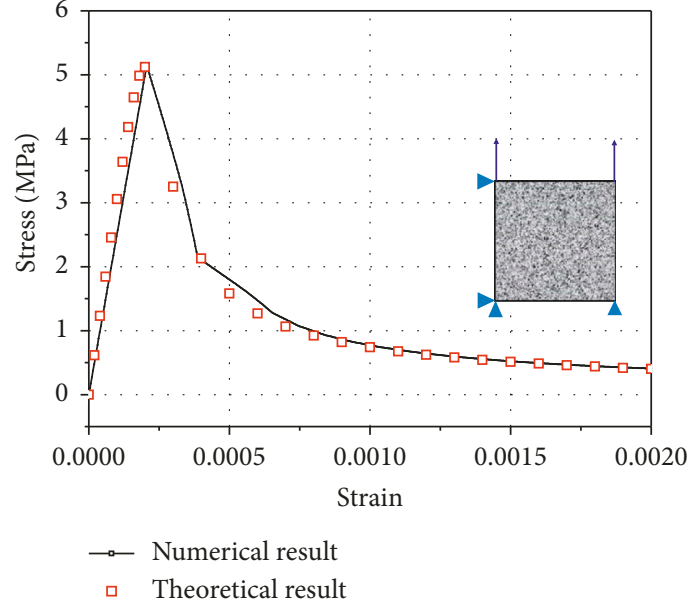

(b)

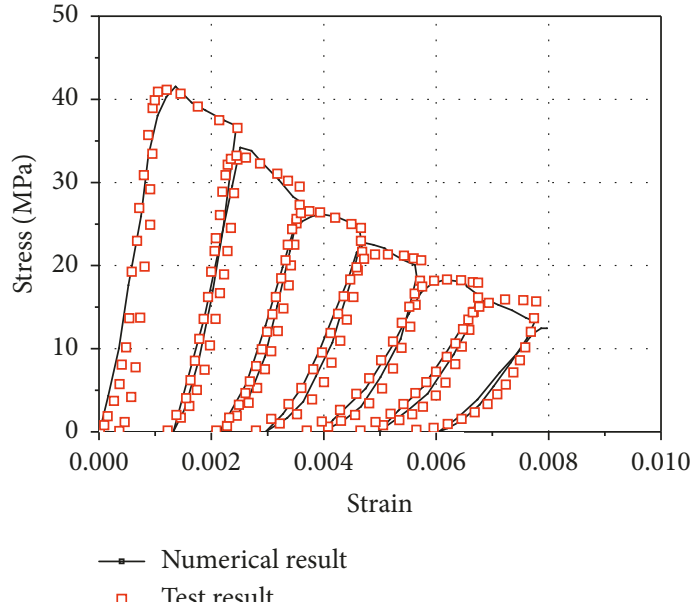

(d)

Figure 21: Material elements modeling under (a) uniaxial monotonic tension [14]; (b) uniaxial monotonic compression [15]; (c) true triaxial compression [16]; (d) uniaxial cyclic compression [58].

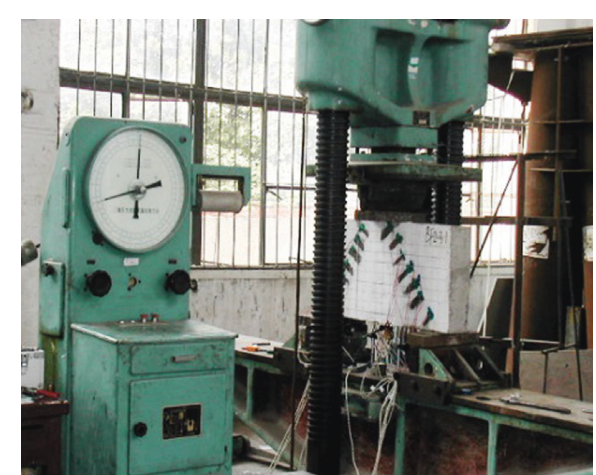

(a)
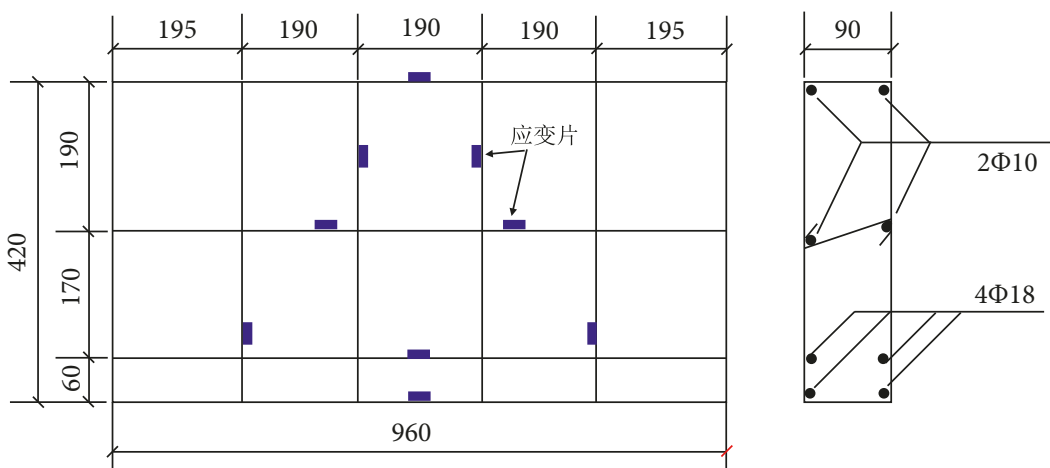

(b)

Figure 22: Experimental program. (a) Test setup. (b) Reinforcement design. 


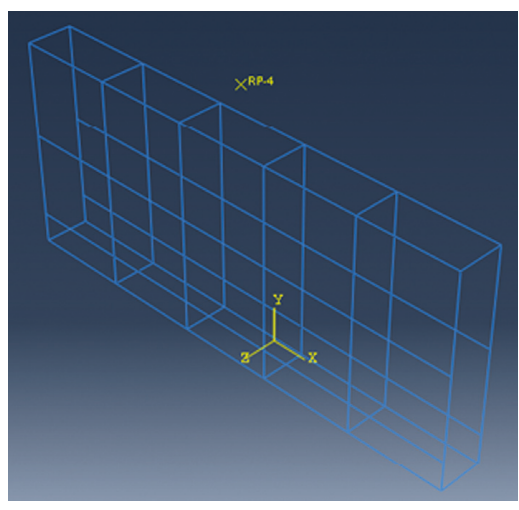

(a)

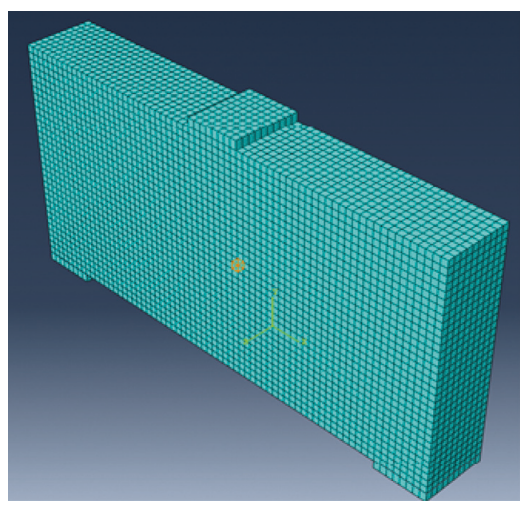

(b)

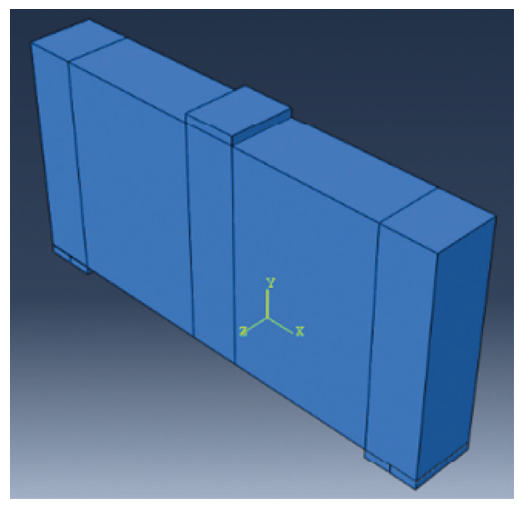

(c)

FIgURE 23: FE model of the HFRC deep beam: (a) steel reinforcements; (b) mesh generation; (c) deep beam model.

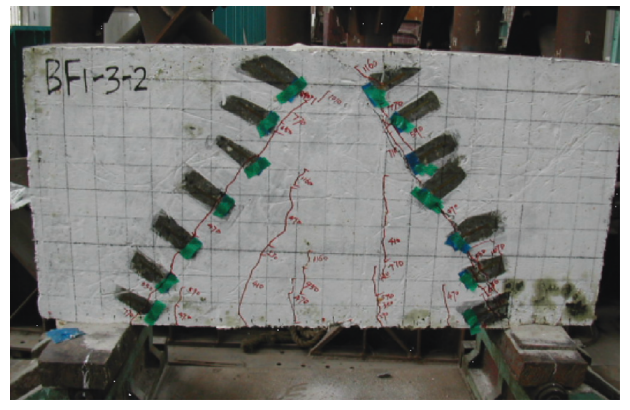

(a)

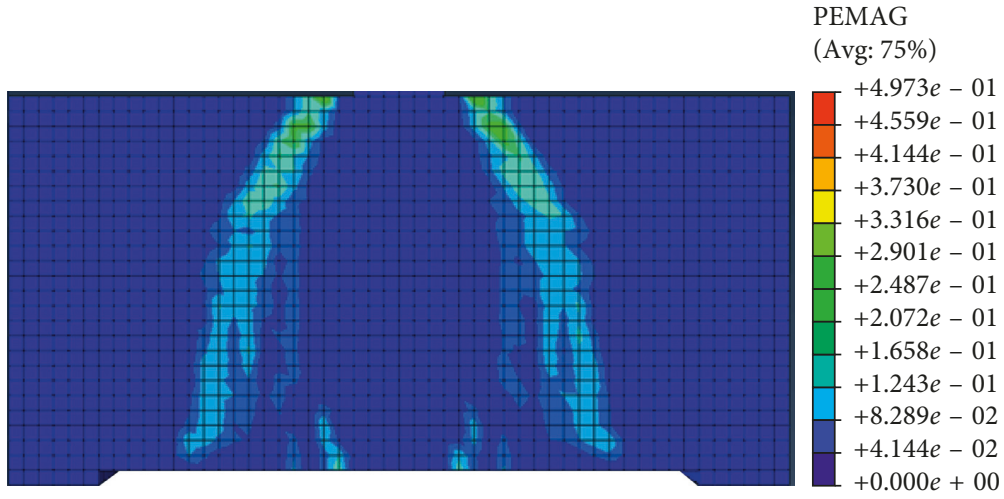

(b)

FIgURE 24: Comparisons of the failure mode of the HFRC deep beam under shear. (a) Numerical result. (b) Test results.

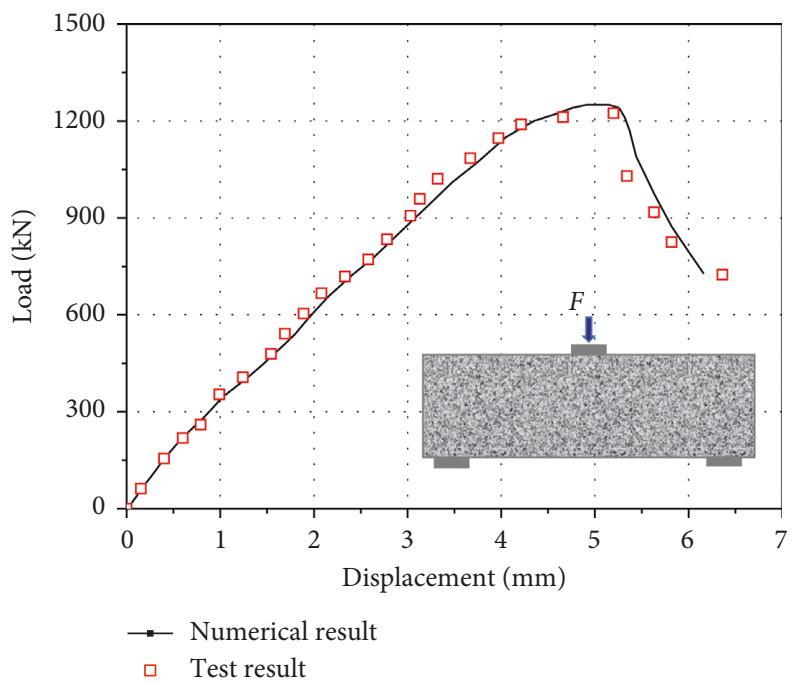

FIgURE 25: Load-deformation curve of the HFRC deep beam under shear.

concrete are also established separately. The embedded region constraint is also used to simulate the interaction between reinforcement and concrete matrix. Moreover, two analytical rigid steel plates are used to tie to the top bottom of the beams. The experimental test setup and instruments are shown in Figure 27(a). A hybrid load-displacement load 


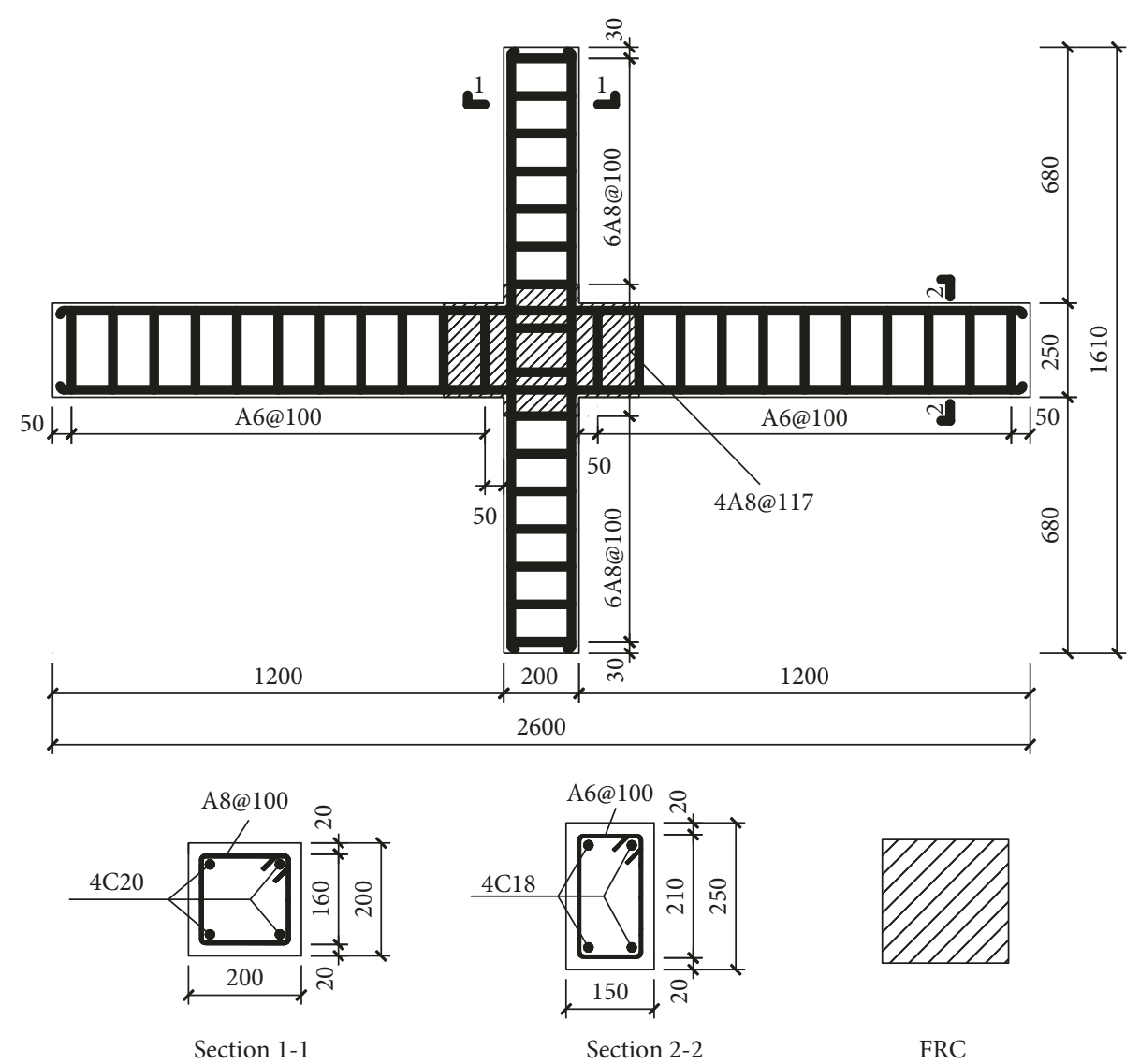

Figure 26: Dimension of the HFRC beam-column joint specimens.

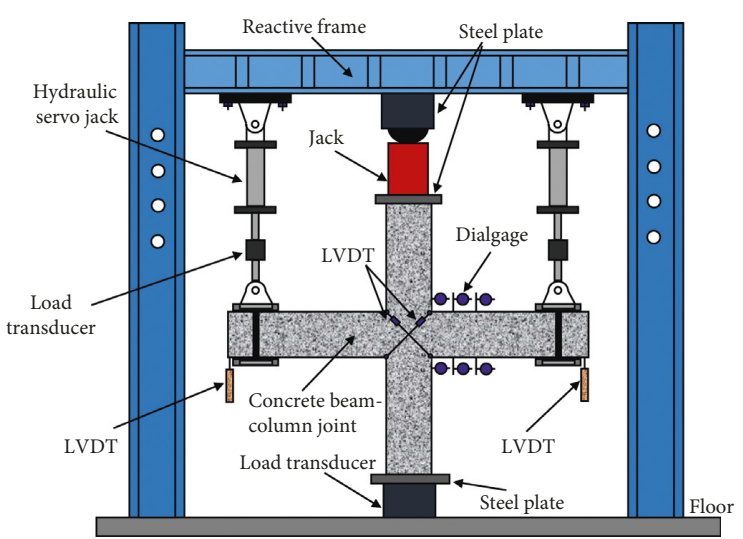

(a)

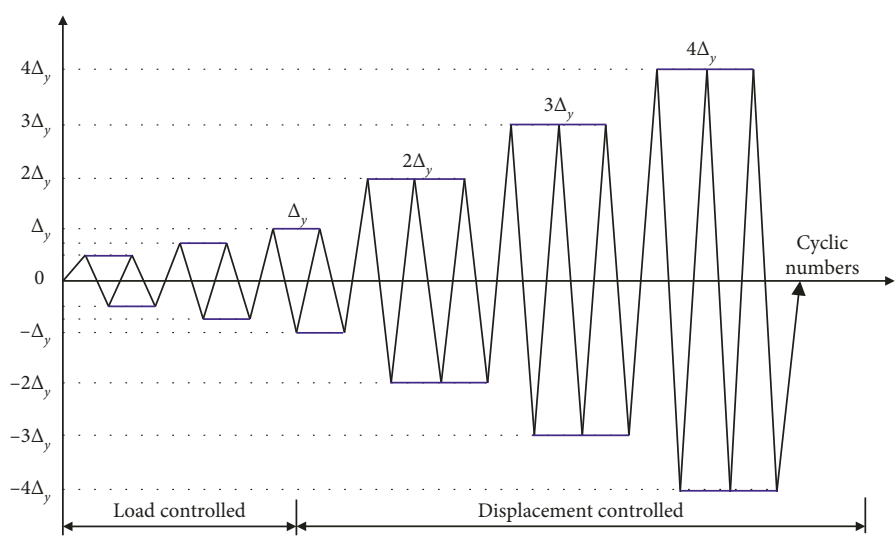

(b)

FIGURE 27: Schematic diagram of (a) setup; (b) loading procedure.

controlled method is applied in this work, as revealed in Figure 27(b). The FE model established is shown in Figure 28.

Figures 29 and 30 exhibit the comparisons of the model results and experimental results of the hysteretic behavior and skeleton as well as the failure pattern of HFRC beamcolumn joints. It is observed from Figure 29 that the simulated hysteretic curve is in good agreement with the test results at the peak point of each cycle. The peak load only has a little difference from each other under each loading cycle; however, the hysteretic loop of the simulated hysteretic curve is fuller than the testing one, and the pinching is far less than the testing curves. The main reasons for this are that the core area of the frame joint of the test specimen is weak, and during the loading process, the crack in the core area is large, which induces an obvious bond slip between steel bar and concrete. Therefore, the hysteresis curve of the test results is seriously pinched. However, the crack development 


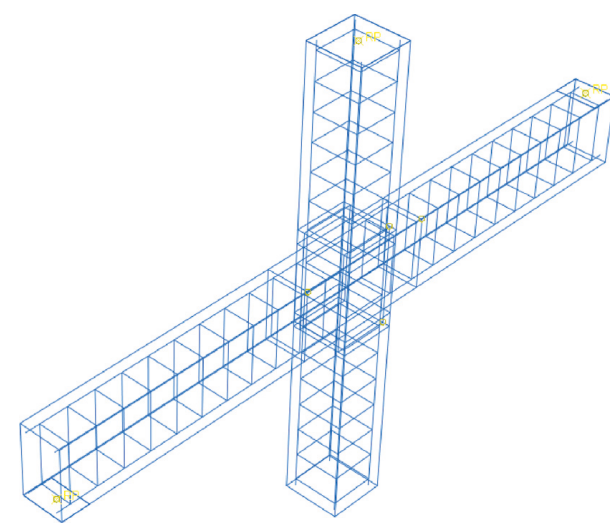

(a)

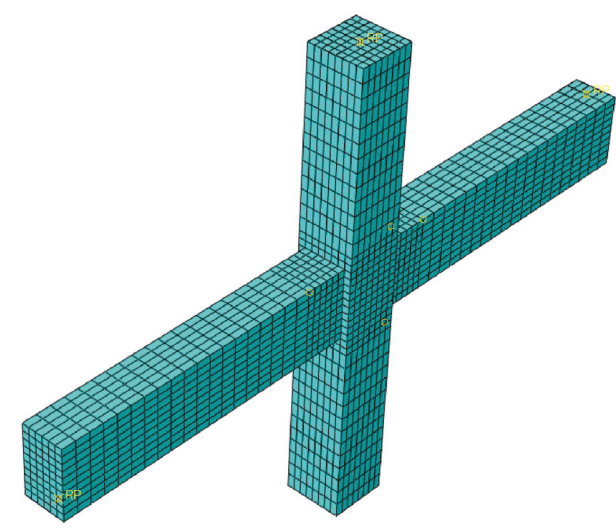

(b)

Figure 28: The FE model of the HFRC beam-column joint under pseudostatic. (a) Discrete model. (b) FE mesh.

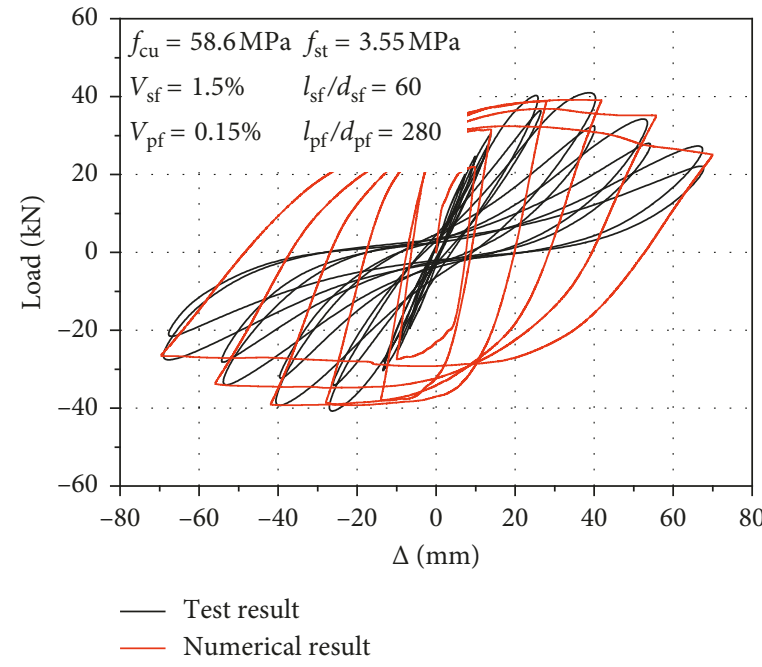

(a)

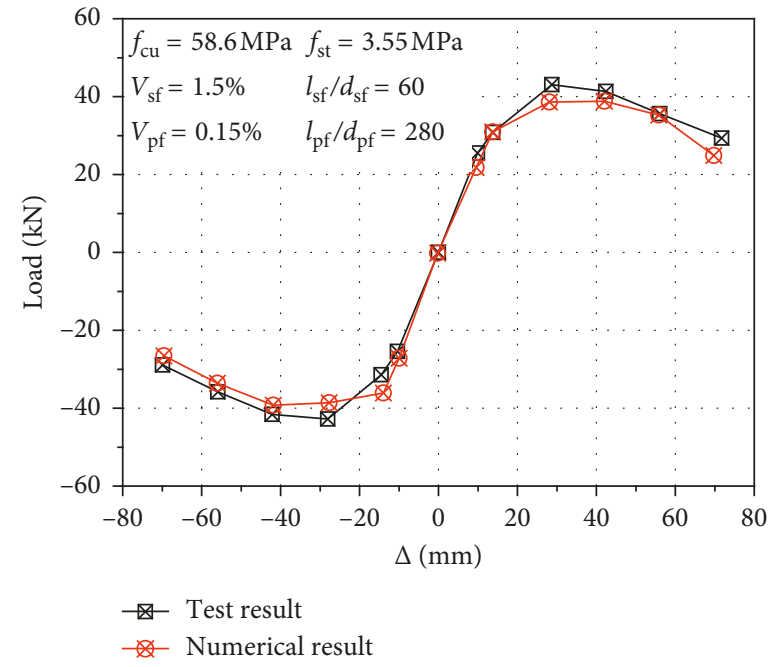

(b)

FIGURE 29: Comparisons of the behavior of HFRC beam-column joints between model prediction and test results. (a) Hysteretic curve. (b) Skeleton curve.

and the bond slip between steel bar and concrete are ignored in the FE model, so the hysteresis curve is very full. With respect to the skeleton curve, it is found that the predicted curve is close to the testing one. The established model can well reflect the mechanical properties of the beam-column joint under seismic loads. Moreover, it is seen from Figure 30 that the failure process by model prediction is consistent with the test results. At the ultimate failure stage, the column end and the adjacent beam ends of concrete as well as the core area of the frame node are seriously damaged, with obvious deformation. These parts are the main stress area of the frame node, while the beam end far from the core area of the frame node is less stressed. Moreover, the external drum of the concrete at the core area of the frame node is observed, which is in line with the vertical expansion of the concrete in the core area and peeling and cracking as well as spalling of the protective layers under the actions of repeated tension and compressive and shear forces. The main stress and deformation areas of the reinforcement are concentrated in and around the core area of the frame joint, and the stress of some of the reinforcement reaches yield strength, which is consistent with the test results. The stresses of steel bars in the core area of the frame joint and the plastic hinge area of the beam end are greater, among which, the most serious stress and deformation is the tensile reinforcement in this range, and some of the hoop reinforcements also reach the yield strength. In addition, the steel at the core area drums significantly, and part of the stirrup stress reaches the yield strength. Meanwhile, the stresses of the stirrups which are farther away from the frame joint core are smaller. The findings indicate that the stirrups of the columns have strong restriction effect of core concrete, but under the concrete and rebar configuration still cannot meet the requirements of "strong frame node"; therefore, it needs to arrange more stirrups in the core to enhance the strength of frame nodes. From the above mentioned analysis, it is obvious that the 


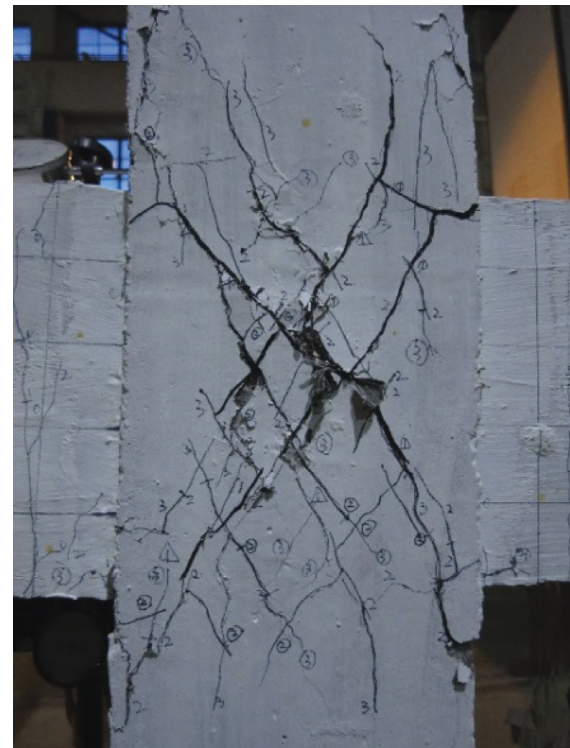

(a)

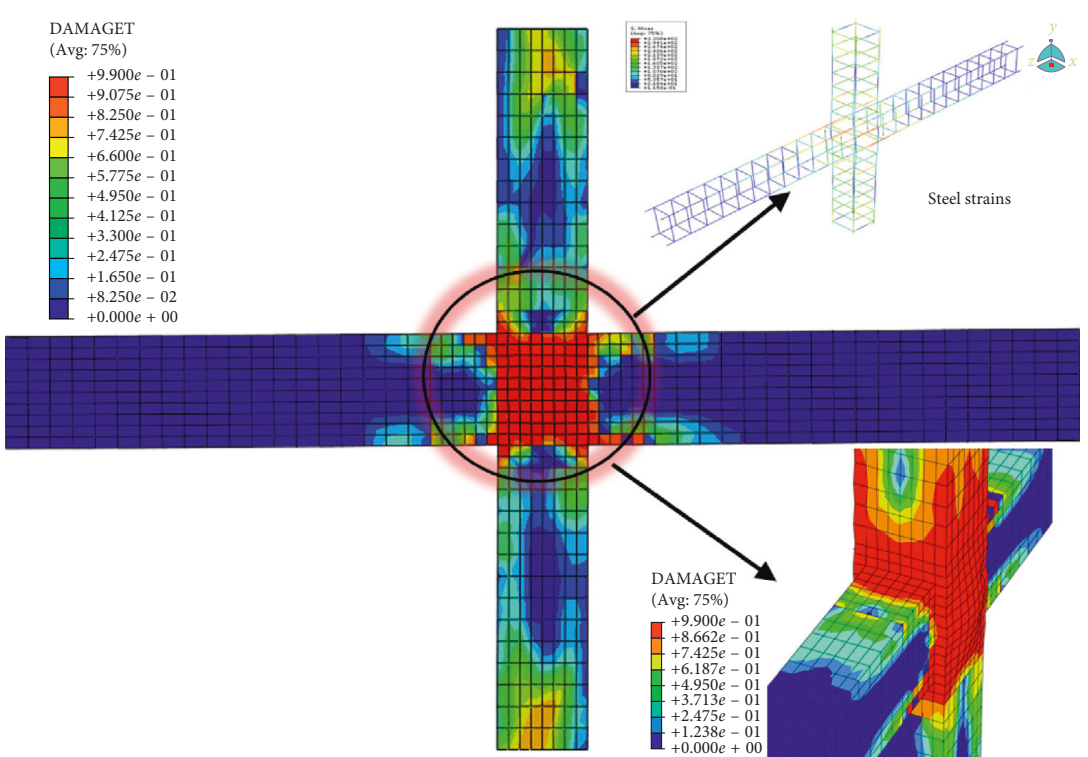

(b)

FIGURE 30: Model results of failure mode of HFRC beam-column joints. (a) Experimental observation. (b) Crack patterns.

model predictions of the seismic behavior of HFRC beamcolumn joint agree well with the experimental results, with a slight difference observed.

\section{Conclusions}

From the present research, the following main conclusions can be drawn:

(1) The addition of hybrid fiber improves the cyclic mechanical properties in terms of peak strength, peak strain, toughness, and postpeak ductility of HFRC under uniaxial tension and compression, which increase with increasing fiber parameters. In the hybrid system, the steel fiber plays the dominant role in the enhancement of cyclic mechanical parameters of HFRC. Moreover, the steel fiber volume fraction on the behaviors of HFRC shows more pronounced effect than that of other factors considered.

(2) Significant stiffness degradation is observed for HFRC under both cyclic tension and compression, which is alleviated by increasing fiber parameters. The energy dissipation of plain concrete and PFRC is insignificant, while that of HFRC is obvious and becomes larger as fiber parameters increase due to the steel fiber sliding and pullout as well as the synergetic effects of hybrid fiber.

(3) The damage of concrete increases with increasing loading cycles, for both cyclic tension and compression, which decreases with an increase in the fiber parameters. Based on the stiffness degradation process, analytical formulae for the damage evolution laws of HFRC are, respectively, suggested for uniaxial tensile and compressive loading cases, with the effects of hybrid fiber taken into consideration.
(4) Based on the test results in previous studies, the concrete damaged plasticity (CDP) model in ABAQUS is modified, with the effects of hybrid fiber taken into consideration. Then, the proposed damage evolution equations under tension and compression combined with the calibrated model are used to predict the mechanical responses of HFRC materials and structural members under static and dynamic loadings. The comparisons between the numerical and experimental results show good agreements.

\section{Data Availability}

The data used to support the findings of this study are available from the corresponding author upon request.

\section{Conflicts of Interest}

The authors declare that they have no conflicts of interest.

\section{Acknowledgments}

This research was conducted at Wuhan University and was financially supported by the National Science Foundation of China under project nos. 51478367 and 51608397.

\section{References}

[1] A. M. Brandt, "Fibre reinforced cement-based (FRC) composites after over 40 years of development in building and civil engineering," Composite Structures, vol. 86, no. 1-3, pp. 3-9, 2008.

[2] R. F. Zollo, "Fiber-reinforced concrete: an overview after 30 years of development," Cement and Concrete Composites, vol. 19, no. 2, pp. 107-122, 1997. 
[3] S. Yazici, G. Inan, and V. Tabak, "Effect of aspect ratio and volume fraction of steel fiber on the mechanical properties of SFRC," Construction and Building Materials, vol. 21, no. 6, pp. 1250-1253, 2007.

[4] C. Jiang, K. Fa, F. Wu, and D. Chen, "Experimental study on the mechanical properties and microstructure of chopped basalt fibre reinforced concrete," Materials and Design, vol. 58, pp. 187-193, 2014.

[5] A. Bhutta, M. Farooq, C. Zanotti, and N. Banthia, "Pull-out behavior of different fibers in geopolymer mortars: effects of alkaline solution concentration and curing," Materials and Structures, vol. 50, no. 1, pp. 1-13, 2017.

[6] K. Wille, M. Xu, S. EI-Tawil, and A. E. Naaman, "Dynamic impact factors of strain hardening UHP-FRC under direct tensile loading at low strain rates," Materials and Structures, vol. 49, no. 4, pp. 1351-1365, 2016.

[7] V. Corinaldesi and A. Nardinocchi, "Influence of type of fibers on the properties of high performance cement-based composites," Construction and Building Materials, vol. 107, pp. 321-331, 2016.

[8] J. Katzer and J. Domski, "Quality and mechanical properties of engineered steel fibers used as reinforcement for concrete," Construction and Building Materials, vol. 34, pp. 243-248, 2012.

[9] H. R. Pakravan, M. Latifi, and M. Jamshidi, "Hybrid short fiber reinforcement system in concrete: a review," Construction and Building Materials, vol. 142, pp. 280-294, 2017.

[10] J. K. Dong, A. E. Naaman, and S. EI-Tawil, "Comparative flexural behavior of four fiber reinforced cementitious composites," Cement and Concrete Composites, vol. 30, no. 10, pp. 917-928, 2008.

[11] T. Uygunoglu, "Investigation of microstructure and flexural behavior of steel-fiber reinforced concrete," Materials and Structures, vol. 41, no. 8, pp. 1441-1449, 2008.

[12] D. Y. Yoo, S. W. Kim, and J. J. Park, "Comparative flexural behavior of ultra-high-performance concrete reinforced with hybrid straight steel fibers," Construction and Building $\mathrm{Ma}$ terials, vol. 132, pp. 219-229, 2017.

[13] M. G. Alberti, A. Enfedaque, and J. C. Galvez, "Fibre reinforced concrete with a combination of polyolefin and steelhooked fibres," Composites Structures, vol. 171, pp. 317-325, 2017.

[14] L. Xu, L. Huang, Y. Chi, and G. Mei, “Tensile behavior of steelpolypropylene hybrid fiber reinforced concrete," ACI Structural Journal, vol. 113, no. 2, pp. 219-229, 2016.

[15] Y. Chi, L. Xu, and Y. Zhang, "Experimental study on hybrid fiber-reinforced concrete subjected to uniaxial compression," Journal of Materials in Civil Engineering, vol. 26, no. 2, pp. 211-218, 2014.

[16] Y. Chi, L. Xu, G. Mei, N. Hu, and J. Su, "A unified failure envelope for hybrid fibre reinforced concrete subjected to true triaxial compression," Composite Structures, vol. 109, pp. 3140, 2014

[17] Y. Chi, L. Xu, and H. Yu, "Constitutive modeling of steelpolypropylene hybrid fiber reinforced concrete using a nonassociated plasticity and its numerical implementation," Composite Structures, vol. 111, pp. 497-509, 2014.

[18] L. Huang, L. Xu, Y. Chi, and H. Xu, "Experimental investigation on the seismic performance of steel-polypropylene hybrid fiber reinforced concrete columns," Construction and Building Materials, vol. 87, pp. 16-27, 2015.

[19] S. Liu and L. Xu, "Shear behavior of hybrid fiber reinforced high performance concrete deep beams," China Civil
Engineering Journal, vol. 46, no. 3, pp. 29-39, 2013, in Chinese.

[20] L. Huang, Y. Chi, L. Xu, P. Chen, and A. Zhang, "Local bond performance of rebar embedded in steel-polypropylene hybrid fiber reinforced concrete under monotonic and cyclic loading," Construction and Building Materials, vol. 103, pp. 77-92, 2016.

[21] L. Xu, F. Deng, and Y. Chi, "Nano-mechanical behavior of the interfacial transition zone between steel-polypropylene fiber and cement paste," Construction and Building Materials, vol. 145, pp. 619-638, 2017.

[22] A. Sivakumar and M. Santhanam, "A quantitative study on the plastic shrinkage cracking in high strength hybrid fibre reinforced concrete," Cement and Concrete Composites, vol. 29, no. 7, pp. 575-581, 2007.

[23] T. Almusallam, S. M. Ibrahim, Y. Al-Salloum, A. Abadel, and H. Abbas, "Analytical and experimental investigations on the fracture behavior of hybrid fiber reinforced concrete," Cement and Concrete Composites, vol. 74, pp. 201-217, 2016.

[24] A. Abadel, H. Abbas, T. Almusallam, Y. A. Al-Salloum, and N. Siddiqui, "Experimental and analytical investigations of mechanical properties of hybrid fiber reinforced concrete," Magazine of Concrete Research, vol. 68, no. 16, pp. 823-843, 2016.

[25] R. S. Chidambaram and P. Agarwal, "Seismic behavior of hybrid fiber reinforced cementitious composite beam-column joints," Materials and Design, vol. 86, pp. 771-781, 2015.

[26] N. Ganesan, P. V. Indira, and M. V. Sabeena, "Behaviour of hybrid fibre reinforced concrete beam-column joints under reverse cyclic loads," Materials and Design, vol. 54, pp. 686693, 2014.

[27] Q. Chen, H. Zhu, Z. Yan, J. W. Jue, Z. Jiang, and Y. Wang, "A multiphase micromechanical model for hybrid fiber reinforced concrete considering the aggregate and ITZ effects," Construction and Building Materials, vol. 114, pp. 839-850, 2016.

[28] S. Kammoun, I. Doghri, L. Adam, G. Robert, and L. Delannay, "First pseudo-grain failure model for inelastic composites with misaligned short fibers," Composites Part A: Applied Science and Manufacturing, vol. 42, no. 12, pp. 1892-1902, 2011.

[29] Y. Chi, M. Yu, L. Huang, and L. Xu, "Finite element modeling of steel-polypropylene hybrid fiber reinforced concrete using modified concrete damaged plasticity," Engineering Structures, vol. 148, pp. 23-35, 2017.

[30] D. Notta-Cuvier, F. Lauro, B. Bennani, and R. Balieu, "Damage of short-fibre reinforced materials with anisotropy induced by complex fibres orientations," Mechanics of Materials, vol. 68, pp. 193-206, 2014.

[31] V. M. C. F. Cunha, J. A. O. Barros, and J. M. Sena-Cruz, "An integrated approach for modelling the tensile behaviour of steel fibre reinforced self-compacting concrete," Cement and Concrete Research, vol. 41, no. 1, pp. 64-76, 2011.

[32] C. Redon and J.-L. Chermant, "Damage mechanics applied to concrete reinforced with amorphous cast iron fibers, concrete subjected to compression," Cement and Concrete Composites, vol. 21, no. 3, pp. 197-204, 1999.

[33] B. Richard, F. Ragueneau, C. Cremona, and L. Adelaide, "Isotropic continuum damage mechanics for concrete under cyclic loading: stiffness recovery, inelastic strains and frictional sliding," Engineering Fracture Mechanics, vol. 77, no. 8, pp. 1203-1223, 2010.

[34] R. Hameed, A. Sellier, A. Turatsinze, and F. Duprat, "Metallic fiber-reinforced concrete behaviour: experimental and 
constitutive law for finite element modeling," Engineering Fracture Mechanics, vol. 103, no. 4, pp. 124-131, 2013.

[35] K. G. Dassios, D. G. Aggelis, E. Z. Kordatos, and T. E. Matikas, "Cyclic loading of a SiC-fiber reinforced ceramic matrix composite reveals damage mechanisms and thermal residual stress state," Composites Part A: Applied Science \& Manufacturing, vol. 44, pp. 105-113, 2013.

[36] H. Fathi and H. Dabbagh, "Damage mechanism of SCC under cyclic loading with different speed," Construction and Building Materials, vol. 101, pp. 252-259, 2015.

[37] B. Li, L. Xu, Y. Chi, B. Huang, and C. Li, "Experimental investigation on the stress-strain of steel fiber reinforced concrete subjected to uniaxial cyclic compression," Construction and Building Materials, vol. 140, pp. 109-118, 2017.

[38] W. Suaris, C. Ouyang, and V. M. Fernando, "Damage model for cyclic loading of concrete," Journal of Engineering $\mathrm{Me}$ chanics, vol. 116, no. 5, pp. 1020-1035, 1990.

[39] M. Breccolotti, M. F. Bonfigli, A. D'Alessandro, and A. L. Materazzi, "Constitutive modeling of plain concrete subjected to cyclic uniaxial compressive loading," Construction and Building Materials, vol. 94, pp. 172-180, 2015.

[40] M. Neuenschwander, M. Knobloch, and M. Fontana, "Suitability of the damage-plasticity modeling concept for concrete at elevated temperatures: experimental validation with uniaxial cyclic compression tests," Cement and Concrete Research, vol. 79, pp. 57-75, 2016.

[41] D. Yankelevsky and H. W. Reinhardt, "Response of plain concrete to cyclic tension," ACI Materials Journal, vol. 84, no. 5, pp. 365-373, 1987.

[42] X. Chen, Y. Huang, C. Chen, J. Lu, and X. Fan, "Experimental study and analytical modeling on hysteretic behavior of plain concrete in uniaxial cyclic tension," International Journal of Fatigue, vol. 96, pp. 261-269, 2017.

[43] P. Jun and V. Mechtcherine, "Behaviour of strain-hardenging cement-based composites (SHCC) under monotonic and cyclic tensile loading Part 1-Experimental investigations," Cement and Concrete Composites, vol. 32, no. 10, pp. 801-809, 2010.

[44] S. A. Paschalis and A. P. Lampropoulos, "Ultra-high performance fiber-reinforced concrete under cyclic loading," ACI Materials Journal, vol. 113, no. 4, pp. 419-427, 2016.

[45] JGJ 55-2011, Specification for Mix Proportion Design of Ordinary Concrete, Ministry of House and Urban-Rural Development of People's Republic of China, China, 2011.

[46] CECS 13:2009, Standard Test Methods for Fiber Reinforced Concrete, China Association for Engineering Construction Standardization, China, 2010.

[47] CSCE 38:2004, Technical Specification for Fiber Reinforced Concrete Structures, China Association for Engineering Construction Standardization, China, 2004.

[48] M. Moretti and T. P. Tassios, "Behaviour of short columns subjected to cyclic shear displacements: experimental results," Engineering Structures, vol. 29, no. 8, pp. 2018-2029, 2007.

[49] L. Jin, D. Li, and X. Du, "Mechanical behavior and size effect of moderate high-strength RC columns under monotonic and cyclic axial compression," Engineering Structures, vol. 124, pp. 269-285, 2016.

[50] ABAQUS, Abaqus Analysis User's Manual Version 6.13, Dassault Systèmes, Waltham, MA, USA, 2013.

[51] T. Tysmans, M. Wozniak, O. Remy, and J. Vantomme, "Finite element modelling of the biaxial behavior of high-performance fibre-reinforced cement composites (HPFRCC) using concrete damage plasticity," Finite Element in Analysis and Design, vol. 100, pp. 47-53, 2015.

[52] J. Lubliner, J. Oliver, S. Oller, and E. Onate, "A plastic-damage model for concrete," International Journal of Solids and Structures, vol. 25, no. 3, pp. 299-329, 1989.

[53] J. Lee and G. L. Fenves, "Plastic-damage model for cyclic loading of concrete structures," Journal of Engineering Mechanics, vol. 124, no. 8, pp. 892-900, 1998.

[54] A. S. Genikomsou and M. A. Polak, "Finite element analysis of punching shear of concrete slabs using damaged plasticity model in ABAQUS," Engineering Structures, vol. 98, pp. 3848, 2015.

[55] T. Yu, J. G. Teng, Y. L. Wong, and S. L. Dong, "Finite element modeling of confined concrete-II: plastic-damage model," Engineering Structures, vol. 32, no. 3, pp. 680-691, 2010.

[56] J. F. Jiang and Y. F. Wu, "Identification of material parameters for Drucker-Prager plasticity model for FRP confined circular concrete columns," International Journal of Solids and Structures, vol. 49, no. 3, pp. 445-456, 2012.

[57] T. C. Rousakis, A. I. Karabinis, P. D. Kiousis, and R. Tepfers, "Analytical modelling of plastic behaviour of uniformly FRP confined concrete members," Composites Part B: Engineering, vol. 39, no. 7, pp. 1104-1113, 2008.

[58] L. Xu, B. Li, Y. Chi, B. Huang, C. Li, and Y. Shi, "Experimental investigation on the stress-strain relation of steelpolypropylene hybrid fiber reinforced concrete subjected to uniaxial cyclic compression," Journal of Building Structures, vol. 39, no. 4, pp. 140-152, 2018, in Chinese. 


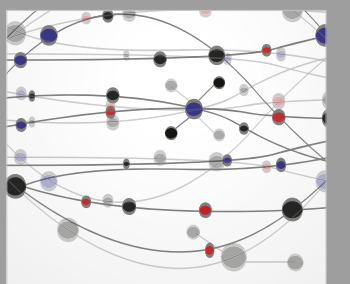

The Scientific World Journal
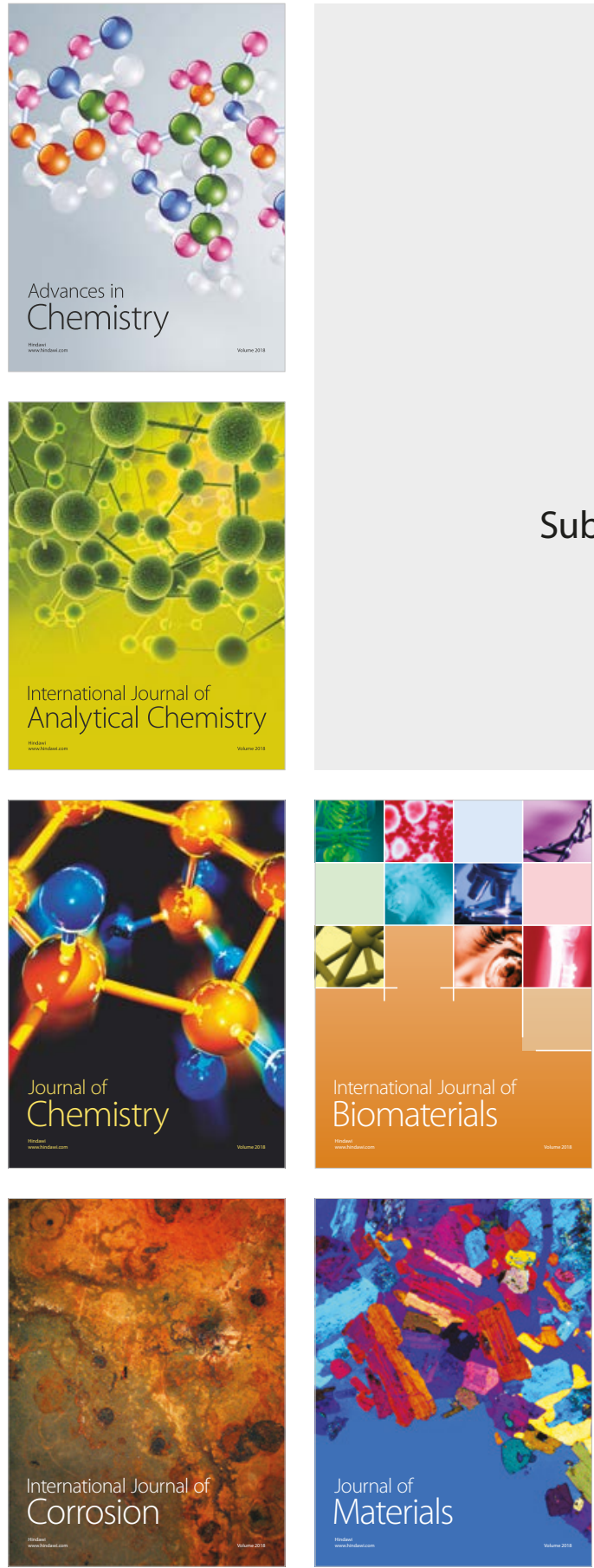

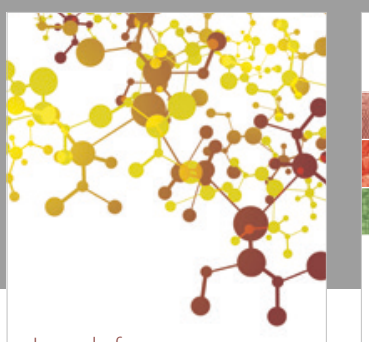

Journal of

Applied Chemistry
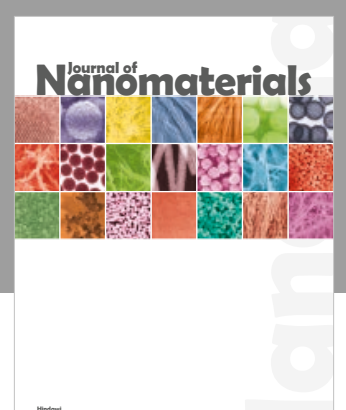

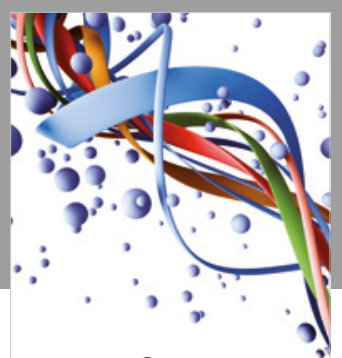

Scientifica

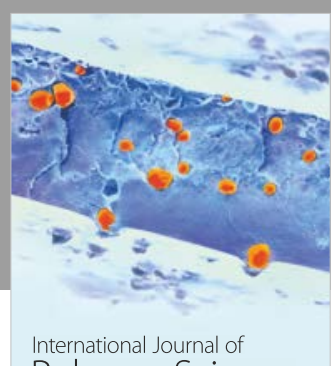

Polymer Science

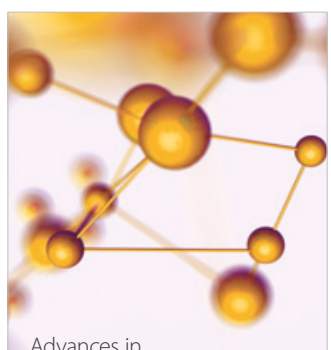

Physical Chemistry
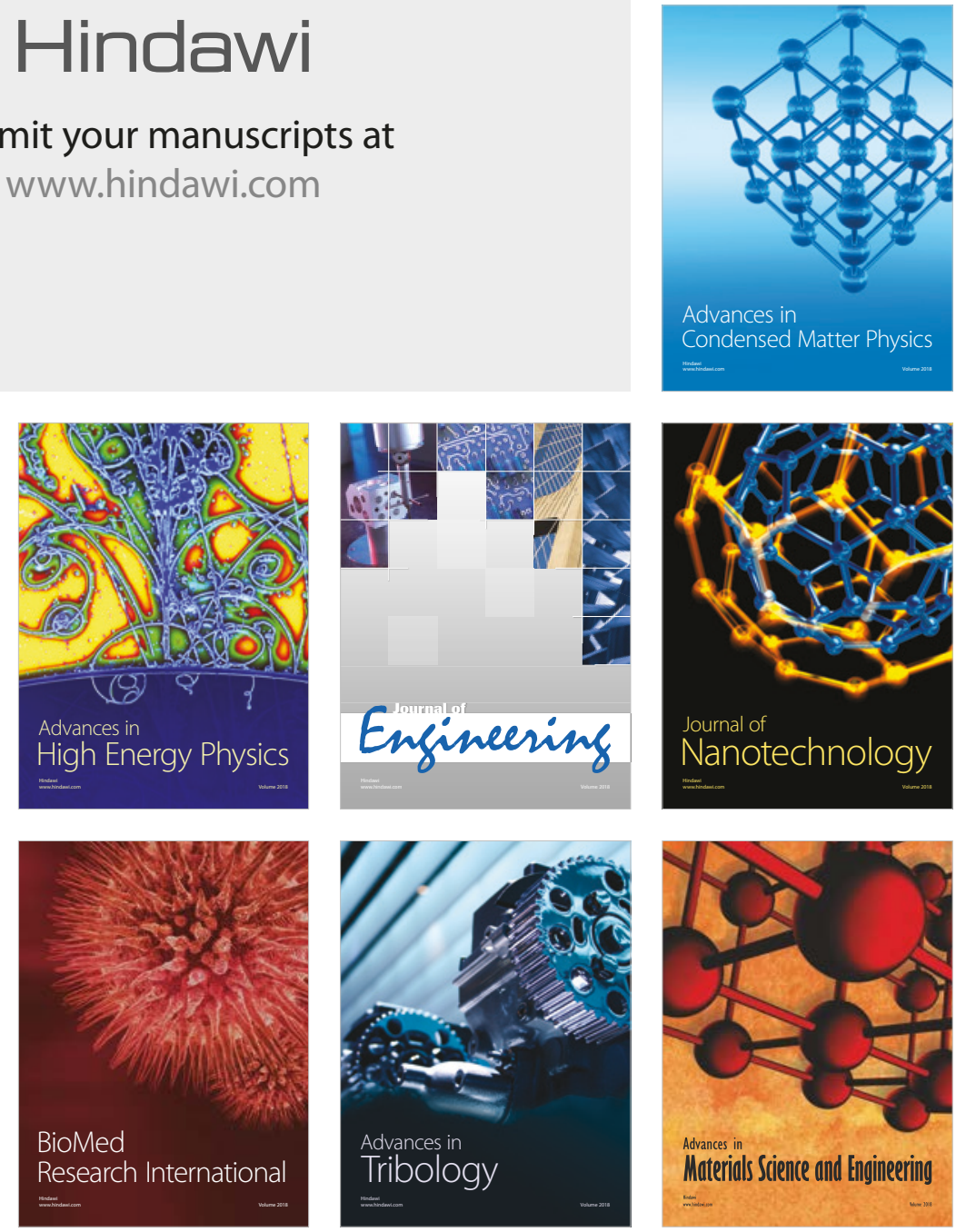